\title{
Tensile Properties of Ingot Iron at Low Temperatures
}

\author{
By Glenn W. Geil and Nesbit L. Carwile
}

\begin{abstract}
True stress-strain curves obtained in tension tests at temperatures ranging from $-196^{\circ}$ to $+100^{\circ} \mathrm{C}$ with ingot iron as annealed, normalized, quenched and tempered, hot-rolled and cold-drawn are presented. Numerous simultaneous load and diameter measurements were made during the entire course of each test. The effects of prior thermal and mechanical treatment of the iron on the true stress-strain relations are discussed.

Graphs are presented showing the influence of the testing temperature, the ferrite grain size, and the initial condition of the iron on the work-hardening characteristics, namely, strain-hardening and strain-aging. The effects of the above factors on yield stress and ultimate stress, and on true stress and true strain at maximum load and at fracture, are presented. The twinning of iron in the tests at low temperatures is briefly discussed.
\end{abstract}

\section{Introduction}

The ordinary tension test is a commonly used method for determining some of the important mechanical properties of materials, namely, proportional limit, yield stress, ultimate stress, breaking stress, percentage elongation, and percentage reduction of area. The procedure for this test has been standardized and is specified in detail in ASTM standards for the Tension Test, ASTM Standards 1946 (E8-46). Stress-strain curves, when drawn, are based on the original dimensions of the specimen. It is desirable, however, to have a tension test reveal more information about the material than is indicated by the above-mentioned properties. This was first pointed out by Ludwik [1] ${ }^{1}$ and discussed in some detail by MacGregor [2], who enumerated many of the advantages obtained by determining a true stress-strain curve for the material tested in tension under controlled test conditions. True stress is the load divided by the minimum area prevailing at that instant. MacGregor has shown that true strain during a tension test may be represented by $\log _{e} A_{0} / A$, in which $A_{0}$ and $A$ represent the initial and the current minimum cross-sectional areas, respectively. If the deformation of the specimen is uniform throughout the gage length and no local contraction occurs before fracture, and assuming the volume of the specimen remains constant, the strain also may be represented by $\log _{e} L / L_{0}$, in which $L_{0}$ and $L$ represent the initial and current gage lengths. However, as shown in a previous paper [4], local contraction may even occur during the deformation between yield and maximum load, and thus simultaneous load and diameter measurements during the entire tension test are essential for an accurate determination of the true stress-strain curve.

Many investigators [2 to 21] have determined true stress-strain curves for various steels tested in tension. Several comprehensive surveys of the literature on the mechanical properties of metals at low temperatures and the flow, fracture, ductility, and workhardening characteristics have been published recently [22 to 28]. Several of the investigators [2, 5 to 11] have reported a linear relationship between

${ }^{1}$ Figures in brackets indicate the literature references at the end of this paper. true stress and true strain from the point representing maximum load to fracture of the specimen. Siegle [12] shows true stress-strain curves obtained with ingot iron tested in tension at temperatures ranging from $-132^{\circ}$ to $23^{\circ} \mathrm{C}$. The diameter measurements were made from photographic images of the specimen taken during the test; although some difficulty was encountered in obtaining good images of the test specimen, especially at a temperature of about $-130^{\circ} \mathrm{C}$ or lower. Siegle's reported results do not conform to a linear true stress-strain relationship from maximum load to fracture. However, only a few experimental points were determined between maximum load and fracture in the tests at subzero temperatures, and some of the irregularity in the data was ascribed to the difficulty of accurately measuring inferior photographic images. Gensamer, Saibel, Ransom and Lowrie [22] state, "It is evident that beyond that point of maximum load, the stress-strain curve in the tensile test is complicated by the introduction of radial and transverse stress components as well as by non-uniformity of the axial stress. The fact that the plot of average stress vs average strain at the minimum section is a straight line from the point of maximum load onward is purely fortuitous."

In previous investigations at this Bureau [16 to 20] in which true stress-strain curves were determined for various steels and nonferrous metals tested in tension at room temperature, the results, in general, do not conform to a linear stress-strain relation from the points representing maximum load to fracture of the specimens.

The purpose of the present investigation was to determine the influence of the testing temperature and various metallurgical factors on the true stressstrain curves and other mechanical properties of ingot iron tested in tension in the temperature range of $-196^{\circ}$ to $+100^{\circ} \mathrm{C}$.

\section{Material and Method of Investigation}

The material used in this investigation was ingot iron. The principal chemical constituents of this material other than iron, as determined by chemical analysis, are (in percent) as follows: carbon, 0.02 ; manganese, 0.02 ; phosphorus, 0.005 ; sulfur, 0.018 ; 
silicon, 0.002 ; copper, 0.10 ; oxygen, 0.058 ; nitrogen, 0.002 ; hydrogen, 0.0005 . This iron was prepared from a single heat and furnished by the manufacturer in the hot-rolled and cold-drawn conditions, with the cold-drawn rods being reduced from hotrolled rods without intermediate annealing. The cold-drawn rods were furnished in two degrees of cold work, namely 14- and 24-percent reduction of area. The iron was studied in the conditions (1) as annealed, (2) as normalized, (3) as quenched and tempered, (4) as hot-rolled, and (5) as colddrawn. The heat treatments that were made at the National Bureau of Standards and applied exclusively to the hot-rolled material are summarized in table 1 . Typical structures of some of these materials are shown in figure 1. The number, size, and distribution of the inclusions are considered normal for ingot iron. The numerous oxide inclusions were dispersed as relatively small particles throughout the ferritic matrix, the massive elongaged inclusions composed essentially of manganese sulfide were elongated in the direction of rolling. Some precipitation occurred in the parent grain boundaries, especially in those specimens that were cooled slowly from $1,750^{\circ}$ or $1,330^{\circ} \mathrm{F}$ to room temperature (fig. $1, \mathrm{~A}, \mathrm{~B}$ and $\mathrm{C}$ ). Iron carbide could be identified in some grain boundaries of the specimens as annealed (fig. 1, A) and as quenched and tempered (fig. 1, B), and it also appeared to be present to a lesser degree in the specimens in each of the other conditions. It would be expected that the relative amount of carbon retained in solid solution should be a minimum in the specimens as annealed or as quenched and tempered, intermediate in the specimens as cold-drawn and a maximum in the specimens as hot-rolled or as normalized. The nitrogen content of this iron was very low $(0.002 \%$ as determined by a modified Allen method), and the amount retained in solid solution should be about the same for each of the initial conditions. Although the phenomenon of strain aging has been attributed by some investigators to the presence of nitrogen, it is expected that this small amount would be ineffective in producing the marked strain-aging observed in some of the tension tests made at temperatures within the range of about $+60^{\circ}$ to $+100^{\circ} \mathrm{C}$.

TABLE 1. Heat treatment of ingot iron a

\begin{tabular}{|c|c|c|c|c|}
\hline Designation & $\begin{array}{c}\text { Diameter } \\
\text { of rod }\end{array}$ & $\begin{array}{c}\text { Tem- } \\
\text { perature }\end{array}$ & Time & Remarks \\
\hline Annealed....- & $\begin{array}{l}\text { in. } \\
0.875\end{array}$ & ${ }^{\circ} F$ & $h r_{1}$ & $\begin{array}{l}\text { Furnace-cooled to } 800^{\circ} \mathrm{F}(20 \\
\text { hr) then air-cooled. }\end{array}$ \\
\hline $\begin{array}{l}\text { Normalized } \\
\text { Quench ed and } \\
\text { tempered. }\end{array}$ & $\begin{array}{r}.875 \\
\text { b. } 500\end{array}$ & $\begin{array}{l}1,750 \\
1,700 \\
1,330\end{array}$ & $\begin{array}{c}1 \\
1 / 2 \\
1\end{array}$ & $\begin{array}{l}\text { Air-cooled. } \\
\text { Quenched in iced brine. } \\
\text { Furnaced-cooled to } 100^{\circ} \mathrm{F} \\
(45 \mathrm{hr}) \text {. }\end{array}$ \\
\hline
\end{tabular}

s All specimens were prepared from hot-rolled rods.

b Specimens machined to approximately $1 / 2$ in. in diameter in reduced sec. tion and $3 / 4$ in. in diameter in shoulders prior to heat treatment.

The ferrite grain size varied considerably in each initial condition of the iron. The average ASTM grain size numbers are given in table 2 , along with some of the mechanical properties of the iron at room temperature. The ferrite grain size was found to be approximately the same for the iron in the conditions as hot-rolled, quenched and tempered, and colddrawn to 14- and 24-percent reduction in area. However, the grain size of the normalized iron was slightly larger, and the grain size of the annealed iron was considerably larger than that of the other conditions.

TABLE 2. Mechanical properties of ingot iron at room temperature

\begin{tabular}{|c|c|c|c|c|c|c|c|c|c|}
\hline \multirow{2}{*}{ Condition } & \multirow{2}{*}{$\begin{array}{l}\text { Hardness } \\
\text { Rockwell B }\end{array}$} & \multirow{2}{*}{$\begin{array}{l}\text { Ferrite } \\
\text { grain size } \\
\text { ASTM No. }\end{array}$} & \multicolumn{2}{|c|}{ Yield stress } & \multirow{2}{*}{$\begin{array}{l}\text { Ultimate } \\
\text { stress }\end{array}$} & \multirow{2}{*}{$\begin{array}{l}\text { True break- } \\
\text { ing stress }{ }^{a}\end{array}$} & \multirow{2}{*}{$\begin{array}{l}\text { Reduction } \\
\text { of area at } \\
\text { maximum } \\
\quad \text { load }\end{array}$} & \multirow{2}{*}{$\begin{array}{l}\text { Reduction } \\
\text { of area at } \\
\text { initial } \\
\text { fracture }\end{array}$} & \multirow{2}{*}{$\begin{array}{l}\text { Reduction } \\
\text { of area at } \\
\text { final } \\
\text { fracture }\end{array}$} \\
\hline & & & Upper & Lower & & & & & \\
\hline $\begin{array}{l}\text { Annealed } \\
\text { Normalized } \\
\text { Quenched and tempered. } \\
\text { Hot-rolled } \\
\text { Cold-drawn } 14 \% \text { reduction of }\end{array}$ & $\begin{array}{l}24 \\
37 \\
31 \\
32\end{array}$ & $\begin{array}{l}2-3 \\
3-4 \\
4-5 \\
4-5\end{array}$ & $\begin{array}{r}1000 \text { psi } \\
16.7 \\
22.3 \\
24.0 \\
29.6\end{array}$ & $\begin{array}{r}1000 \text { psi } \\
14.7 \\
20.5 \\
20.5 \\
24.7\end{array}$ & $\begin{array}{r}1000 \text { psi } \\
41.2 \\
43.7 \\
39.7 \\
43.3\end{array}$ & $\begin{array}{r}1000 \text { psi } \\
85.0 \\
95.2 \\
88.4 \\
105.0\end{array}$ & $\begin{array}{l}\text { \% } \\
23.7 \\
23.3 \\
23.6 \\
23.2\end{array}$ & $\begin{array}{l}\% \\
67.0 \\
69.5 \\
71.2 \\
74.9\end{array}$ & $\begin{array}{ll}\% & \\
& 72.1 \\
74.4 \\
76.0 \\
78.4\end{array}$ \\
\hline area.... & 78 & $4-5$ & \multicolumn{2}{|c|}{ b 60} & 65.0 & 98.0 & 5.6 & 56.0 & 61.4 \\
\hline $\begin{array}{l}\text { Cold-drawn } 24 \% \text { reduction of } \\
\text { area. }\end{array}$ & 86 & $4-5$ & \multicolumn{2}{|c|}{ b 72} & 73.2 & 100.9 & 4. 3 & 49.1 & 56.1 \\
\hline
\end{tabular}

a At initial fracture.

b No drop of beam, stress at $0.2 \%$ offset.

Cylindrical tensile specimens with a reduced section of 2 -in. gage length were used. The reduced section. was gradually tapered from each end; the diameter at the midsection of the gage length was about 0.003 in. less than that at the ends. A minimum gage diameter of 0.438 in. instead of the standard $0.505 \mathrm{in}$. was employed to avoid fracture in the threaded ends of the specimens during testing at low temperatures. The specimens were finished to the final dimensions by grinding and polishing in the axial direction, to avoid circumferential tool marks from acting as transverse notches. The ends of the specimen were machined with $3 / 4-$ in. $\times 10$ threads and the shoulder fillets were machined to a radius of $1.5 \mathrm{in}$.

A pendulum hydraulic testing machine of 50,000-lb capacity was used for these tests. To obtain the desired test temperatures, the specimens, except for those tested at room temperature, were fully immersed in an appropriate liquid contained in a cylindrical vessel. One threaded end of the specimen passed through the bottom of the cylindrical vessel into the lower adapter of the testing machine. Lead washers were used at this position to seal 
against loss of the bath liquid. The outside of the vessel was covered with several layers of wool felt for thermal insulation. The felt in turn was enclosed with a covering of thin sheet aluminum to prevent condensation of moisture on the felt. The upper and lower adapters were made as long as the clearance of the testing machine would permit. When the test temperature was $-78^{\circ} \mathrm{C}$ or lower, the adjacent portions of the head and base of the testing machine were surrounded with pulverized solid $\mathrm{CO}_{2}$ to minimize the temperature gradient in the adapters.

For obtaining test temperatures of $+100^{\circ}$ and $+60^{\circ} \mathrm{C}$, the bath, water with sodium chromate added as an inhibitor to corrosion, was heated with an electrical immersion heater. For temperatures between room $\left(27^{\circ}\right.$ to $\left.30^{\circ} \mathrm{C}\right)$ and $-78^{\circ} \mathrm{C}$, a bath mixture of equal parts by volume of carbon tetrachloride and chloroform was cooled by the gradual addition of small quantities of pulverized $\mathrm{CO}_{2}$. A temperature of $-78^{\circ} \mathrm{C}$ was maintained in the carbon tetrachloride-chloroform bath with an excess of pulverized $\mathrm{CO}_{2}$. For temperatures of $-120^{\circ}$, $-138^{\circ}$, and $-154^{\circ} \mathrm{C}$, a bath of dichloro-difluoromethane (Freon 12) was cooled by passing liquid nitrogen through an immersed copper coil; the bath was stirred constantly with an electric stirrer. A chromel-alumel thermocouple was attached to the specimens at the upper end of the reduced gage section for measuring the test temperature. For temperatures of $-188^{\circ}$ and $-196^{\circ} \mathrm{C}$, the specimens were fully immersed in baths of liquid air and liquid nitrogen, respectively.

The rate of loading was less than is usual in a tension test to avoid local heating of the specimens during the plastic deformation. The loading was so controlled that the rate of contraction of the specimens beyond the initial yielding was maintained at approximately 1-percent reduction of area per minute. The maintenance of this rate of contraction of the specimen after the maximum load had been reached was achieved by a gradual closing of the control valve on the hydraulic testing machine.

A common type of reduction-of-area gage with wedge anvils was used for determining the change in the minimum diameter of the specimen during the tension tests at room temperature. However, this gage could not be used with the tests at other temperatures. A reduction-of-area gage of special design, which could function satisfactorily while largely submerged in the bath, was constructed for use at subzero and moderately elevated temperatures. A detailed description of the gage and its calibration and manipulation is given in a previous paper [4]. Changes in diameter of a specimen can be measured by this instrument with an accuracy of $\pm 0.0001 \mathrm{in}$.

\section{True Stress-Strain Curves}

The true stress-strain curves obtained for specimens of ingot iron as annealed, normalized, quenched and tempered, hot-rolled and cold-drawn, tested in tension at temperatures ranging from $-196^{\circ}$ to $+100^{\circ} \mathrm{C}$, are given in figures 2 to 7 . A scale of actual values of $A_{0} / A$ is given at the top of each diagram for convenience in comparing these results with previous results obtained at this Bureau [16 to $20]$, in which the data were plotted on this scale. The true stress values at the initiation of fracture as obtained during test through the use of the reductionof-area gage will be designated in this paper as the fracture stresses, whereas the points designated as crosses are the values usually reported as the true breaking stresses or fracture stresses. The latter values are obtained by dividing the load at initial fracture by the minimum area of the specimen as determined from diameter measurements made after the specimen has been fractured. Fracture of an unnotched specimen tested in tension is usually initiated at its axis, and the crack propagates toward the periphery; the metal at the periphery often extends longitudinally and contracts radially during the fracture. This "rim effect" varies with the composition, structure, and condition of the metal, as well as the temperature during the tension test. Thus, fracture stress values as determined from diameter measurements made after fracture of a ductile specimen may be of little significance.

The true stress-strain curves (figs. 2 to 7 ) obtained for ingot iron specimens tested at temperatures ranging from $-196^{\circ}$ to $+100^{\circ} \mathrm{C}$ do not conform to a linear relationship for the portion of the curves between the points representing maximum load and either initial or complete fracture. This portion of the curves is absent for all specimens tested at $-196^{\circ}$ $\mathrm{C}$, except for hot-rolled ingot iron, as fracture occurred before the maximum load conditions were attained. The divergence from a linear relationship usually increases slightly as the testing temperature is lowered. The divergence also varies with the initial condition of the iron and is greater for the normalized, annealed, and hot-rolled specimens than for the quenched and tempered and cold-drawn specimens.

The plastic deformation was not uniform along the gage length during the testing of the ingot iron, irrespective of the initial conditions. Some local contraction even occurred during initial yielding of the iron. At a strain value slightly above the yield, the minimum diameter of the specimen usually continued to decrease and the region of local contraction extended longitudinally along the gage length. In some specimens, however, local contraction occurred in two or more regions. As the strain approached that produced by the ultimate stress, the trend was for the specimen to become nearly cylindrical throughout its entire gage length. After the ultimate stress was attained, the specimen started to contract locally (neck) in the usual manner, and this condition continued to complete fracture. It should be pointed out, however, that the change in deformation with stress in this range, ultimate to fracture, frequently occurred in a cyclic manner as illustrated by the position of the experimental points given for the hotrolled specimens tested at $-120^{\circ}$ and at $-138^{\circ} \mathrm{C}$ (fig. 5). 
The nonuniform deformation associated with pronounced strain-aging is manifested by the serrations in the true stress-strain curves for some of the tests at $+100^{\circ} \mathrm{C}$. Oscillations of the pendulum of the testing machine occurred during the deformation from yield to fracture. The magnitude of the oscillations at $+100^{\circ} \mathrm{C}$ varied both with the degree of strain and the initial condition of the iron. For annealed, hot-rolled, and cold-drawn specimens, the oscillations were relatively small throughout the range of strain from the initial yielding to the maximum load; the magnitude generally increased slightly during the earlier portion of this range and decreased during the latter portion to very small values at the maximum load. At strains considerably greater than that at maximum load, the magnitude of the oscillations suddenly increased greatly and continued in this manner as the specimens wẹre extended to fracture. The oscillations for the quenched and tempered specimen were relatively small and were observed only in the first half of the strain range from initial yielding to maximum load. For the normalized specimen, the oscillations were relatively small immediately following initial yielding, but increased continuously as the specimen was extended to fracture. Only variations in the true stress-strain curves corresponding to the larger oscillations are shown in figures 2 to 7 . Smaller and less uniform oscillations also were observed in some of the tests at $60^{\circ} \mathrm{C}$.

The change in diameter of the specimen during each oscillation could be followed with the reductionof-area gage. The diameter decreased rapidly during each drop of the pendulum. It remained almost constant during the subsequent rise of the pendulum until the load reached a critical value and a new oscillation was initiated. The strain-aging and strainhardening of the metal resulting from the rapid deformation that accompanied the drop of the pendulum apparently was of sufficient magnitude to prevent further deformation until the true stress was again increased to a new critical value by an increase of the applied load.

The locus of fracture curves, $L$, (figs. 2 to 7 ) are drawn through the points representing initial fracture at the various temperatures and depict the influence of the testing temperature on the fracture stress and strain at fracture of the ingot iron in each of the initial conditions. The influence of the testing temperature on the strain at fracture varies with the initial condition, and this may result in a large change in the shape of these curves as illustrated by the double reversal in curvature in those for the normalized and hot-rolled specimens (figs. 3 and 5) in contrast to the absence of reversals in those for the other specimens (figs. 2, 4, 6, 7). The influence of these factors will be reported in more detail later in the discussion of the diagrams representing the influence of the testing temperature on the mechanical properties of the iron.

\section{Influence of Temperature on the Work- Hardening Characteristics}

The most satisfactory method of studying the work-hardening of metals is by means of the relation between true stress and true strain in a simple tension test in which the load and the change in diameter of the specimen are accurately measured throughout the entire test. As the term "workhardening" relates to the increase of the true stress, $\sigma$, with increase in the true strain, $\delta,\left(\delta=\log _{e} A_{0} / A\right)$, the slope of the true stress-strain curve, $d \sigma / d \delta)$, at any strain is a measure of the instantaneous rate of work-hardening at that strain. If aging or recovery occurs during the tension test, the total workhardening is the combined effect of these factors and the ordinary strain-hardening, and $d \sigma / d \delta$ represents the instantaneous rate of the total workhardening.

Several investigators $[8,10,22,28$ to 31$]$ have presented data indicating that the true stress-strain relationship for metals tested in tension is parabolic and may be expressed mathematically as follows

$$
\sigma=k \delta^{m},
$$

in which $k$ and $m$ are constants, characteristic of the material. According to this relationship, the true stress and true strain values plotted on logarithmic coordinates should conform to a straight-line graph with the slope of the line equal to $m$. The coefficient $m$ is generally designated the strain-hardening coefficient, and the rate of work-hardening is given by

$$
\frac{d \sigma}{d \delta}=m \frac{\sigma}{\delta}
$$

if the relationship expressed in eq 1 is valid.

It should be pointed out, however, that many of the logarithmic true stress-strain curves, presented as evidence confirming the above parabolic relationship (eq 1) were plotted on scales of equal logarithmic cycle length for both axes, thus giving lines of very small slope. Any deviations from a linear relationship are not detected easily in graphs of this kind.

Now let any general relationship be assumed between the true stress $\sigma$ and the true strain $\delta$, namely $\sigma=f(\delta)$. If $\sigma$ and $\delta$ are plotted on logarithmic coordinates, the slope, $b$, of such a curve at any point would be:

$$
b=\frac{d\left(\log _{e} \sigma\right)}{d\left(\log _{e} \delta\right)}=\frac{d \sigma}{\sigma} / \frac{d \delta}{\delta},
$$

and as

$$
\delta=\log _{e} A_{o} / A
$$

then

$$
d \delta=-d A / A \text {. }
$$


Substituting in eq 3, one obtains

$$
\frac{d \sigma}{\sigma} / \frac{d A}{A}=-b / \delta
$$

At the upper and lower yield points and at maximum load (where $d L=d(\sigma A)=0)$

$$
\frac{d \sigma}{\sigma}=-\frac{d A}{A} \text {. }
$$

Substituting in eq 6 , one obtains

$$
\delta=b .
$$

Therefore, the slope of a logarithmic true stressstrain curve at the upper and lower yield points and at the maximum load is equal to the respective strains at these points.

By substituting $b=\delta$ in eq 3 , one obtains the relation

$$
\frac{d \sigma}{d \delta}=\sigma
$$

Thus, the rate of work-hardening at the upper and lower yield points and at the maximum load is equal to the respective true stresses at these points.

The relation expressed in eq 9 has been developed in a slightly different manner by Gensamer [29] and by Voce [21]. The relation, $\delta=m$ at the maximum load has been developed by Hollomon [10], although it was based on the true stress-strain relationship given in eq 1. However, as shown in the development presented above (eq 3 to 9 ), the relationships given in eq 8 and 9 do not depend upon any specified true stress-strain relation.

Hollomon [10] presented evidence indicating that the relationship $\sigma=k \delta^{m}$ was valid for plastic deformation beyond the end of initial yielding to that at the maximum load or to strains of about 0.4 for steels tested in tension. The results obtained in the present investigation, however, do not confirm this relationship; the true stress-strain values plotted on logarithmic coordinates do not necessarily show a linear relationship. Some of the data obtained in tension tests at various temperatures with the hot-rolled ingot iron are presented in figure 8 . It should be noted that in this figure the length of a logarithmic cycle on the scale of true stress is twice that for the scale of true strain. This method of plotting reveals the curvature of these lines. The dashed lines in this figure are drawn through the points $U$, representing true stress-strain values at the maximum load, with the slopes of the lines equal to the strains at the maximum load $(b=\delta)$. The true stress-strain values in the immediate vicinity of the maximum load conform very closely to these dashed lines. These lines, however, do not pass through the points, $E$, representing the end of the initial yielding. ${ }^{2}$ Moreover, the true stress-strain

2 In this investigation, the end of the nearly horizontal portion of the loadextension curve associated with the lower yield point was considered as the end of the initial yielding. values for deformation between the end of initial yielding and maximum load cannot be represented accurately by a straight line. Similar results were obtained in tension tests with the ingot iron in the other initial conditions. Thus, no constant workhardening coefficient can be determined from these tension tests, and the work-hardening rates cannot be derived readily from the logarithmic true stressstrain graphs.

The work-hardening rate, $d \sigma / d \delta$, at any strain can be ascertained from the slope of the true stress-strain curves (figs. 2 to 7 ) at the designated strain, although some difficulty may be encountered in accurately determining the tangent line to the curve at the designated strain value. On the other hand, an average work-hardening rate, $\Delta \sigma / \Delta \delta$, over a range of strain $\Delta \delta$ can be determined readily from the true stress-strain curves. This method has been used in this investigation to determine the influence of temperature on the work-hardening characteristics of the ingot iron during the tension test. The results are summarized in figures 9 to 13 . As the strain, $M$, at the minimum point of the true stress-strain curve after initiation of yielding varies with the temperature of the specimen, it was deemed advisable to choose this point as the initial reference point for the $\Delta \delta$ values. Thus the average work-hardening rates at the various temperatures for a specified strain range at the small strains are established from approximately corresponding portions of the true stress-strain curves. The broken-line curve through the completely filled circles in each figure represents the influence of the testing temperature on the rate of work-hardening at the maximum load, $(d \sigma / d \delta=\sigma)$. Straight lines tangent to the true stress-strain curves at the maximum load point have slopes that agree very closely with the value of the true stress at the maximum load. These data are summarized in table 3.

All of the sets of curves in figures 9 to 13 have several features in common. The curves are generally lowered as the strain of the specimen increases; this change is greatest for the small strains and progressively decreases in magnitude as the strain increases. At the larger strains (strains from maximum load to fracture) the decrease in. work-hardening: rate with increase in strain is relatively small except at the very low temperatures. At very low temperatures the curves $A$ for the smallest strain range, $M$ to $M+0.02$ drop below some of those for the progressively larger strains. This factor reflects the influence of the testing temperature on the initial yielding of the specimen. At room temperature or at slightly elevated temperatures, the degree of heterogeneous deformation during the initial yielding was very small, and the corresponding true stressstrain curves (figs. 2 to 7 ) rise sharply after reaching the minimum true stress. ${ }^{3} \quad$ As the testing temperature

${ }^{3}$ The minimum of the true stress-strain curve at which $d \sigma / d \delta=0$, occurs at a slightly smaller strain than that at the minimum load of the lower yield point. At the latter point the slope of the true stress-strain curve must be positive and equal to the value of the true stress. The physical significance of the portion of the curves representing the initial yielding may be questionable, as these curves are based on average values of the true stress and strain during the heterogeneous deformation. 
TABLE 3. Rate of work-hardening of ingot iron specimens at the maximum load (1,000 psi)

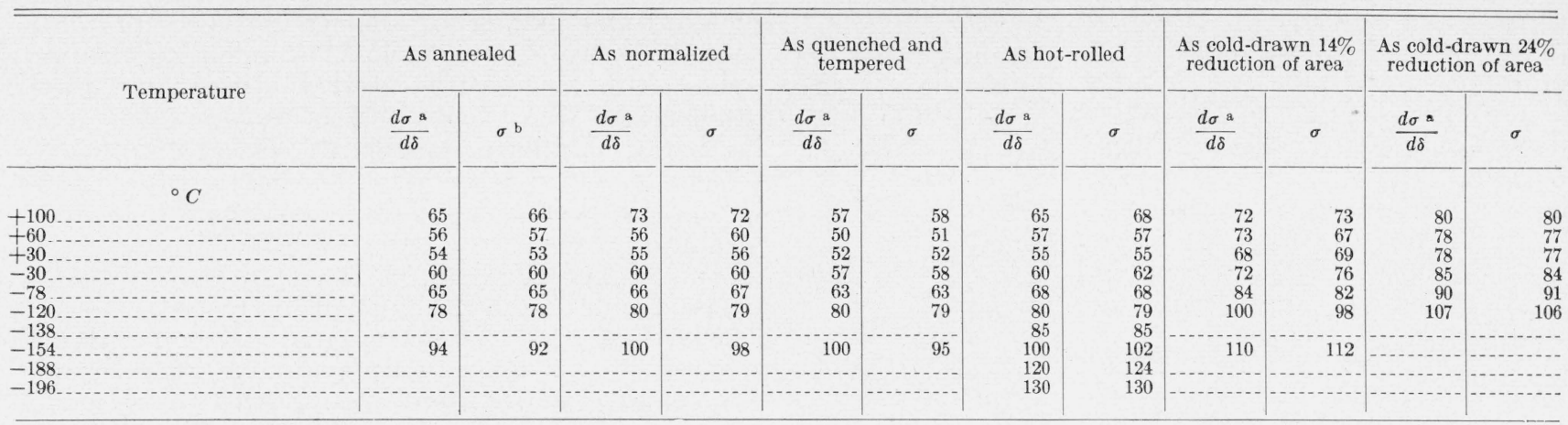

s Slope of tangent line to the true stress-strain curve at the maximum load. b True stress at the maximum load.

is lowered, the strain during the initial yielding increases and the curve rises less abruptly beyond the minimum point. At the low temperatures, the relatively flat portion of the curve is an appreciable proportion of the total strain range $\Delta \delta$ from $M$ to $M+0.02$, and this factor is the cause of the lowering of the work-hardening curves $A$ at the low temperatures. The sharp rise in these curves for the temperature range of room to $+100^{\circ} \mathrm{C}$ is a result of the large increase in the magnitude of the strainaging of the iron during the tension test.

The curves $B$ to $I$ of figures 9 to 13 are not appreciably affected by the sharpness of the rise of the true stress-strain curves beyond the minimum point, except curve $B$ for the iron in the cold-drawn conditions. These curves are representative of the influence of the testing temperature on the total work-hardening characteristics of the iron for the designated strain ranges. They show a general trend of a decrease in the rate of total work-hardening with increase in temperature from $-196^{\circ}$ to about $-120^{\circ} \mathrm{C}$ for some curves and from $-154^{\circ}$ to about $-120^{\circ} \mathrm{C}$ for others. As the temperature is increased from $-120^{\circ}$ to $-30^{\circ} \mathrm{C}$, the total workhardening rates for any specified strain range either remains approximately constant or increases. The work-hardening rates decrease as the temperature is increased from $-30^{\circ}$ to about $+30^{\circ} \mathrm{C}$ and increase again as the temperature is raised to $+100^{\circ} \mathrm{C}$.

The rate of total work-hardening of the iron at the maximum load, irrespective of its initial condition, decreases continuously as the temperature is raised from $-196^{\circ}$ to about $+30^{\circ} \mathrm{C}$ in some cases and from $-154^{\circ}$ to about $+30^{\circ} \mathrm{C}$ in other cases, and usually increases with further increase of the temperature to $+100^{\circ} \mathrm{C}$. These curves are not a comparison of work-hardening rates at a constant strain, as the strain at maximum load in each case varied greatly with the testing temperature. They indicate the influence of the testing temperature on the rate of work-hardening of the iron at the maximum load conditions (eq 7, 8, and 9).

The portions of the total work-hardening curves ( $B$ to $I$ in figs. 9 to 12 ) for temperatures ranging from $-196^{\circ}$ to $-120^{\circ} \mathrm{C}$ for some curves and from $-154^{\circ}$ to $-120^{\circ} \mathrm{C}$ for the others manifest the influ- ence of a decrease in strain-hardening with increase in temperature, as the total work-hardening at these temperatures is mainly strain-hardening. However, as the temperature is increased above $-120^{\circ} \mathrm{C}$, the strain-aging becomes a significantly influencing factor in increasing the total work-hardening rates, and the magnitude of this factor is as great or greater than the decrease in the ordinary strainhardening rates. Above about $+30^{\circ} \mathrm{C}$, the influence of the strain-aging predominates, and the total workhardening rates increase greatly.

Another factor that probably has considerable influence on the variation of the rate of workhardening with temperature is the mechanism of deformation. Deformation by twinning (Neumann bands) occurred in the specimens tested in tension at temperatures below $-120^{\circ} \mathrm{C}$, but no evidence of this was found in specimens tested at temperatures above $-120^{\circ} \mathrm{C}$. The extent of twinning during the tension test increased as the temperature was lowered from $-120^{\circ}$ to $-196^{\circ} \mathrm{C}$ as illustrated by the microstructures (fig. 14) for the hot-rolled ingot iron. The twinning occured to a similar extent in the iron tested in the conditions as annealed, normalized, and quenched and tempered (fig. 15). The twinning in the iron in the conditions as cold-drawn was restricted to the portion of the specimens adjacent to the fracture, whereas it occurred throughout the entire gage length of the specimens of the iron in the other conditions (figs. 14 and 15). As twinning occurred in specimens deformed in tension but not extended to fracture at the low temperatures, it is considered that this phenomenon in iron is not primarily associated with the plastic deformation at the instant of fracture or any accompanying shock waves.

A comparison of graphs of work-hardening rates versus temperature (figs. 9 to 13 ) reveals that the initial condition of the iron influences the rate of total work-hardening at the various strain ranges up to about the strain at maximum load. The amount of carbon initially retained in solid solution and the size of the ferrite grains apparently affected the rate of work-hardening $(\Delta \sigma / \Delta \delta)$ in this range of deformation. The curves $A, B, C$, and $D$ for the quenched and tempered iron (fig. 11) show lower 
work-hardening rates at most of the testing temperatures, especially in the range from about $+30^{\circ}$ to $+100^{\circ} \mathrm{C}$, than the corresponding curves for the normalized (fig. 10) or hot-rolled (fig. 12) irons. These lower values for the quenched and tempered iron probably are caused mainly by a decrease in the strain-aging as a result of the smaller amount of carbon retained in solid solution. The workhardening rates were usually higher for the annealed (fig. 9) than for the quenched and tempered iron (fig. 11). As the amount of carbon retained in solid solution was approximately the same for the irons in these two conditions, the higher work-hardening rates of the annealed iron can be attributed to its coarser ferrite grains (ASTM No. 2 and 4, table 2). The rates for the annealed iron, in general, were slightly higher than those of either the normalized or hot-rolled irons, although the amount of carbon initially retained in solid solution of the annealed material was also lower than that of the other two conditions. This change in the positions of the curves may be attributed to the predominant effect of the coarser grain size of the annealed iron. Thus the rise in true stress between yield and maximum load is more rapid for the annealed iron than for the normalized or hot-rolled irons. The work-hardening characteristics of the normalized (fig. 10) and hotrolled (fig. 12) irons were approximately alike, except in the temperature range of about $+30^{\circ}$ to $+100^{\circ} \mathrm{C}$, in which the strain-aging of the normalized iron was appreciably greater. The amount of carbon in solid solution prior to testing was considered to be about the same for the hot-rolled as for the normalized material. The rates of the work-hardening of the iron reduced 14 and 24 percent in area by cold-drawing, are considerably less than those of the iron in the other conditions. The strain-hardening and strain-aging accompanying the 14- and 24percent reductions in area of the hot-rolled iron were greater when the iron was reduced by colddrawing and subsequently aged in storage than when the reduction was obtained in an ordinary tension test.

\section{Influence of Temperature on the Mechanical Properties}

The influence of the testing temperature on yield stress, ultimate stress, true stresses at maximum load and at fracture, and true strains at maximum load and at fracture can be readily determined from the tension tests made at the various temperatures and the true stress-strain curves obtained from these tests. These data, as summarized in figures 16 to 21 , show the relationship of some of these properties. It is apparent that the ratio of the values of true stress at maximum load to the ultimate stress for these curves will depend upon the strain at maximum load. The strains at maximum load varied considerably with the test temperature and the initial condition of the iron and usually decreased greatly at the very low temperatures. Thus some of the pairs of curves of ultimate stress, and true stress at maximum load, actually converge at the lowest temperatures.
The dependence of the true stress at fracture on the strain at fracture is clearly shown in these figures and will be discussed later.

The combined effects of test temperature and initial condition of the iron on the above-mentioned mechanical properties are depicted in the composite diagrams of figures 22 to 27 . The curves for the lower yield stress (fig. 22) depict closely the effect of temperature on the initial strength (initial resistance to flow) of the iron in the various conditions. The effect of strain-aging during the initial yielding on the yield strength was relatively small or negligible at temperatures in the range $0^{\circ}$ to $-196^{\circ} \mathrm{C}$. The lower yield stress, and hence the initial strength of the iron, increased continuously with lowering of the temperature in this range; this increase in yield stress with lowering of the temperature from $0^{\circ}$ to $-196^{\circ} \mathrm{C}$ was about $70,000 \mathrm{psi}$ for the iron in each of the initial conditions. At temperatures in the range of $0^{\circ}$ to $+100^{\circ} \mathrm{C}$, however, the strain-aging of the iron during the initial yielding was usually appreciable and is depicted by a leveling off or a slight rise of the curves with increase in temperature in this range. Thus these curves do not necessarily indicate an increase in the initial strength of the irons with increase in temperature from $0^{\circ}$ to $+100^{\circ} \mathrm{C}$.

The combined effects of the ferrite grain size and the solubility of carbon on the initial strength of the iron are indicated in the relative positions of the yield stress curves (fig. 22). The hot-rolled iron (ASTM grain No. 4 to 5) and the normalized iron, (ASTM grain No. 3 to 4 ) should have about the same amount of carbon retained in solid solution. At each test temperature throughout the range of $-196^{\circ}$ to $+100^{\circ} \mathrm{C}$, however, the yield stress of the hot-rolled material (curve $B$ ) is higher than the corresponding yield stress of the normalized material (curve $F^{\prime}$ ). Similarly, curve $E$, for the quenched and tempered iron (ASTM grain No. 4 to 5), is higher throughout this temperature range than curve $A$, for the annealed iron (ASTM grain No. 2 to 3), even though both conditions are considered to have about the same amount of carbon retained in solid solution. These results show a general trend of an increase in yield stress as the ferrite grain size decreases. It is noteworthy, however, that the relatively high yield strengths (curves $C$ and $D$ of fig. 22) and also the relatively high ultimate stresses and true stresses at maximum load (curves $C$ and $D$ of figs. 23 and 24) of the cold-drawn irons are due to the strain-hardening and strain-aging during the prior cold-drawing operations and the aging during storage. These high-strength values are not due to a grain size factor, as the average ferrite grain size was the same for the hot-rolled, quenched and tempered, and cold-drawn conditions.

The ultimate stress (fig. 23) and true stress at maximum load (fig. 24) both increased as the test temperature was decreased from about $+30^{\circ}$ to $-196^{\circ} \mathrm{C}$; the true stress at maximum load of the annealed specimens did not change appreciably as the temperature was decreased from $-154^{\circ}$ to $-196^{\circ} \mathrm{C}$. Both stresses either changed little or 
increased slightly as the temperature was raised from about $+30^{\circ}$ to $+60^{\circ} \mathrm{C}$, and both increased considerably as the temperature was raised from $+60^{\circ}$ to $+100^{\circ} \mathrm{C}$, because of the increase with temperature of the strain-aging accompanying the deformation. The strain-aging varies with the initial condition of the iron and especially with the amount of carbon initially retained in solid solution. Thus, the ultimate stresses and true stresses at maximum load for the hot-rolled iron (curves $B$ ) are relatively higher at temperatures above $-120^{\circ} \mathrm{C}$ than those for the quenched and tempered iron. (curves $E$ ), even though the average grain size was the same. These values for the normalized iron (curves $F$ ) are relatively higher at most of the test temperatures above $-120^{\circ} \mathrm{C}$, than those for the annealed iron (curves $A)$. This would be expected, as the normalized iron. initially had a smaller ferrite grain size and retained more carbon in solid solution. However, it is believed the effect of the ferrite grain size on the strain-aging was relatively small. The increase in. ultimate stress and true stress at maximum load with increase in temperature in the range $+60^{\circ}$ to $+100^{\circ} \mathrm{C}$ for the cold-drawn iron (curves $C$ and $D$ ) was relatively small, as appreciable strain-aging had occurred during cold-drawing and subsequent storage. At the very low temperatures, $-154^{\circ}$ to $-196^{\circ} \mathrm{C}$, the relative positions of the curves of true stress at maximum load (fig. 24) depend greatly upon the strain at maximum load; the greater the strain the greater is the true stress.

The curves representing the influence of test temperature on true strain at maximum load are shown in figure 25. The strains at maximum load for the annealed (curve $A$ ), hot-rolled (curve $B$ ), normalized (curve $F$ ), and quenched and tempered (curve $E$ ) irons show certain common features. The strains remained approximately constant at test temperatures ranging from $+60^{\circ}$ to $-30^{\circ} \mathrm{C}$ and, in general, decreased as the temperature was lowered from $-30^{\circ}$ to $-196^{\circ} \mathrm{C}$. The curve $B$ for the hotrolled iron however, exhibits a moderate increase in strain as the temperature is lowered from about $-125^{\circ}$ to $-160^{\circ} \mathrm{C}$; a smaller increase is also noted in the curve $F$ for the normalized iron. At a temperature of $-196^{\circ} \mathrm{C}$, the strains at maximum load apparently were influenced greatly by the ferrite grain size; the larger the grain size the smaller was the strain. The strain for the annealed iron was considerably smaller than that for the quenched and tempered iron. The iron in both conditions was considered to have about the same amount of carbon. initially retained in solid solution. Similarly, the strain at $-196^{\circ} \mathrm{C}$ for the normalized iron was considerably smaller than that of the hot-rolled iron.

The strains at maximum load for the cold-drawn irons (curves $C$ and $D$ ), as a result of the strainhardening and strain-aging prior to test are very much smaller than those for the iron in the other conditions. It should be pointed out, however, that the temperatures at which the strain begins to decrease rapidly with decrease in temperature are about
100 deg. C lower for the cold-drawn irons than for the other irons.

The curves representing the influence of test temperature on the true strain at fracture are shown in figure 26 ; the true strain at fracture is a measure of the ductility of a metal. Curves $A, E, C$, and $D$ for the annealed, quenched and tempered, and cold drawn irons are similar in shape. As the temperature is decreased from $+100^{\circ}$ to $-196^{\circ} \mathrm{C}$, the ductility first gradually rises to a maximum and then decreases continuously to very low values at $-196^{\circ} \mathrm{C}$. There is no abrupt change in the slope of these curves $(A, E, C$, and $D)$ and no sharp transition temperature. ${ }^{4}$ The ductility at fracture of the hot-rolled and normalized irons varied considerably with the test temperature, and two maxima are exhibited in each curve (curves $B$ and $F$ ). The ductility was greatly reduced as the temperature was lowered from $-30^{\circ}$ to $-78^{\circ}$ for curve $F$, and to $-120^{\circ} \mathrm{C}$ for curve $B$. With further decrease in temperature to $-154^{\circ} \mathrm{C}$, however, the ductility increased slightly and then decreased greatly as the temperature was lowered to $-196^{\circ} \mathrm{C}$. As mentioned earlier, the curves representing the ductility at maximum load of the iron in these two conditions (fig. 25) exhibit the same trend, although to a smaller extent. This characteristic is probably associated in some way with the greater amount of carbon initially retained in solid solution in these irons than in the other irons.

The temperature at which the maximum ductility is retained depends upon the initial condition of the iron (fig. 26). This temperature is highest for the normalized iron, curve $F$, and lowest for the colddrawn iron, curves $C$ and $D$. The temperature of the maximum ductility of the cold-drawn irons is about $50^{\circ} \mathrm{C}$ below that of the hot-rolled iron, curve $B$. The reduction in the amount of carbon retained in solid solution by the strain-aging of the iron during the cold-drawing operations and storage resulted in a shift of the temperature of maximum ductility to a lower value.

The fracture stress curves (fig. 27) indicate a general trend of an increase in fracture stress with decrease in temperature between $+30^{\circ}$ and about $-160^{\circ}$ C. However, many deviations from this trend are shown in the curves. All of the stress values are decreased as the temperature is lowered from about $-160^{\circ}$ to $-196^{\circ} \mathrm{C}$ because of the large decrease in ductility. The increase in the fracture stress values accompanying a rise of testing temperature from $+60^{\circ}$ to $+100^{\circ} \mathrm{C}$ is due to the predominant influence of the strain-aging. The curves $B$ and $F$ for the hot-rolled and normalized irons exhibit a large decrease in fracture stress values as the temperature is lowered from about $-30^{\circ}$ to about $-80^{\circ} \mathrm{C}$, a direct result of the rapid decrease in ductility of the specimens as the temperature is lowered through this range (fig. 26).

The influence of prior cold-drawing of the hotrolled iron on the fracture stress, as determined in

${ }^{4} \mathrm{~A}$ transition temperature is generally considered as a narrow temperature range in which the fracture changes from a shear to a clearage type accompanied by a large decrease in ductility. 
subsequent tension tests, is also illustrated in figure 27 by the shape of the curves $B, C$, and $D$. The strain-hardening and strain-aging accompanying the cold-drawing of the iron and aging during subsequent storage did not completely remove all of the characteristics specific to the hot-rolled iron. Curve $C$ for the iron reduced 14 percent in area by cold-drawing: exhibits a smaller dip in the region near $-78^{\circ} \mathrm{C}$ than that in curve $B$ for the hot-rolled iron. Colddrawing of the iron to 24-percent reduction in area was sufficient to eliminate the dip in the fracture stress curve $D$ in the region near $-78^{\circ} \mathrm{C}$.

The reduction of the amount of carbon retained in solid solution by a heat treatment of the initially hot-rolled iron, such as represented by the quenched and tempered, or annealed condition, also influences the fracture stresses as indicated by a nearly continuous rise of the curves $E$ and $A$ of figure 27 as the temperature is lowered from about $+30^{\circ}$ to about $-160^{\circ} \mathrm{C}$.

\section{Summary}

True stress-strain curves for ingot iron in various conditions and tested in tension at temperatures ranging from $-196^{\circ}$ to $+100^{\circ} \mathrm{C}$, are presented. Derived graphs also are presented showing the effects of the testing temperature and initial condition of the ingot iron on the mechanical properties and work-hardening characteristics.

The true stress-strain curves for tension tests at temperatures ranging from $-196^{\circ}$ to $+100^{\circ} \mathrm{C}$ with annealed, normalized, quenched and tempered, hotrolled and cold-drawn ingot iron are not linear between maximum load and fracture; the divergence from a linear relationship generally increases as the testing temperature is lowered.

The logarithmic graphs of the true stress-strain data for ingot iron tested in tension at temperatures ranging from $-196^{\circ}$ to $+100^{\circ} \mathrm{C}$ are not linear, and thus the true stress-strain relationship cannot be represented accurately by the equation, $\sigma=k \delta^{m}$.

The plastic deformation of the ingot iron is not uniform during extension. Some local contraction usually occurs at the initial yielding of the iron and during deformation between yield and maximum load. The deformation from maximum load to fracture is frequently nonuniform, as indicated by a cyclic trend in this portion of the true stress-strain curves.

The "rim effect" obtained during the fracture of ingot iron is considerable except at the very low testing temperatures. Accurate values of the fracture stress, therefore, cannot be determined from diameter measurements of the ingot iron specimens after fracture, except possibly for those tested at very low temperatures.

Deformation by twinning (Neumann bands) occurs during the deformation of specimens of ingot iron tested in tension at temperatures below $-120^{\circ} \mathrm{C}$, and the amount of twinning depends upon the testing temperature and the prior strain history of the specimen; the twinning increases with decrease of temperature below $-120^{\circ} \mathrm{C}$ and decreases with prior cold-working of the iron at room temperature.

The work-hardening of ingot iron during test in tension at temperatures below $-120^{\circ} \mathrm{C}$ is mainly strain-hardening, and the rate of total work-hardening increases with decrease in the testing temperature. As the temperature is increased above $-120^{\circ}$ $\mathrm{C}$, the influence of strain-aging in increasing the total work-hardening rate appears to be appreciable. Above room temperature strain-aging is the predominating factor, and the total work-hardening rate increases greatly with increase in temperature.

The effect of the ferrite grain size is manifested in the yield stress values; the yield stress decreases with increase in the grain size. The work-hardening rates at very small strains also are influenced by the ferrite grain size; the rate increases with increase in the grain size. The difference in the grain size of the iron in the various initial conditions, however, was not sufficient to greatly affect the other mechanical properties.

The variation of the strains at maximum load and at fracture with temperature, as determined in tension tests, depends upon the initial condition of the iron; it varies with the amount of carbon retained in solid solution and the prior strain history. The transition temperature ranges, as determined by variations in the strains at fracture, in general, are relatively broad.

The fracture stress curves (true stress at initial fracture) show a trend of an increase in the fracture stress values with decrease in testing temperature below room temperature. However, several factors, such as strain-hardening, strain-aging, and strain at fracture greatly influence the fracture stresses and result in many deviations from this trend.

The authors are indebted to C. R. Johnson, R. L. Bloss, Lavaria B. Weinrich, and Fannie A. Wilkinson for assistance in this investigation.

\section{References}

[1] P. Ludwik, Elemente der technologischen Mechanik (Julius Springer, Berlin, 1909).

[2] C. W. MacGregor, The true stress-strain tension testits role in modern materials testing, J. Franklin Inst. 238, 111, 159 (1944).

[3] E. Voce, True stress-strain curves, Metal Treatment 15, 53 (summer 1948).

[4] G. W. Geil and N. L. Carwile, A reduction-of-area gage for use at low temperatures, J. Research NBS 43, 527 (1949) RP2044.

[5] C. W. MacGregor, Relation between stress and reduction in area for tensile tests of metals, Trans. Am. Inst. Min. Met. Engrs. 124, 208 (1937).

[6] M. Gensamer, E. B. Pearsall, and G. V. Smith, The mechanical properties of the isothermal decomposition products of austenite, Trans. Am. Soc. Metals 28, 380 (1940).

[7] C. E. Lacy and M. Gensamer, The tensile properties of alloyed ferrites, Trans. Am. Soc. Metals 32, 88 (1944).

[8] J. H. Hollomon, The effect of heat treatment and carbon content on the work hardening characteristics of several steels, Trans. Am. Soc. Metals 32, 123 (1944).

[9] C. Zener and J. H. Hollomon, Plastic flow and rupture of metals, Trans. Am. Soc. Metals 33, 163 (1944).

[10] John H. Hollomon, Tensile deformation, Trans. Am. Inst. Min. Met. Engrs. 162, 268 (1945). 
[11] T. A. Read, H. Markus, and J. M. McCaughey, Plastic flow and rupture of steel at high hardness levels - part of book Fracturing of metals, Am. Soc. Metals (Cleveland, Ohio, 1948).

[12] L. Siegle, Effect of ferritic grain size on the true stressstrain tensile properties and notch impact strength of ingot iron at low temperatures. Thesis presented to the Graduate School, Univ. Pennsylvania (1948).

[13] E. J. Ripling, Tensile properties of a heat treated low alloy steel at subzero temperatures, Am. Soc. Metals Preprint No. 1 (1949).

[14] E. J. Ripling and G. Sachs, The effect of strain-temperature history on the flow and fracture characteristics of an annealed steel, J. Metals 1, Sec. 3, 205 (1949).

[15] J. E. Dorn, A. Goldberg, and T. E. Tietz, The effect of thermal-mechanical history on the strain hardening of metals, Trans. Am. Inst. Min. Met. Engrs. 180, 205 (1949).

[16] D. J. McAdam, Jr., G. W. Geil, and W. D. Jenkins, Influence of plastic extension and compression on the fracture stress of metals, Trans. Am. Soc. Testing Materials 4\%, 554 (1947).

[17] D. J. McAdam, Jr., G. W. Geil, and R. W. Mebs, Influence of plastic deformation, combined stresses and low temperatures on the breaking stress of ferritic steels, Trans. Am. Inst. Min. Met. Engrs. 17\%, 323 (1947).

[18] D. J. McAdam, Jr., G. W. Geil, D. H. Woodard, and W. D. Jenkins, Influence of size and the stress system on the flow stress and fracture stress of metals, Trans. Am. Inst. Min. Met. Engrs. 180, 363 (1949).

[19] D. J. McAdam, Jr., G. W. Geil, and Frances Jane Cromwell, Flow, fracture and ductility of metals, Trans. Am. Inst. Min. Met. Engrs. 175, 306 (1948).
[20] D. J. McAdam, Jr., G. W. Geil, D. H. Woodard, and W. D. Jenkins, Influence of strain aging on the fracture stress of low carbon steel, Trans. Am. Inst. Min. Met. Engrs. 176, 436 (1948).

[21] E. Voce, The relationship between stress and strain for

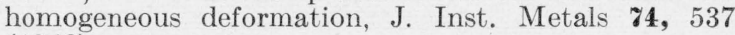
(1948).

[22] M. Gensamer, E. Saibel, J. T. Ransom, and R. E. Lowrie, The fracture of metals (Am. Weld. Soc., New York, N. Y., 1947).

[23] L. Siegle and R. M. Brick, mechanical properties of metals at low temperatures: A survey, Trans. Am. Soc. Metals 40, 813 (1948).

[24] J. H. Hollomon, The problem of fracture, Welding J. 25, Res. Supplement 534s (1946).

[25] H. W. Gillett and F. T. McGuire, Behavior of ferritic steels at low temperatures, Nat. Research Council War Met. Comm. Reports No. W-78 and W-118 (June 1944).

[26] A. E. White and C. A. Siebert, Report on literature survey on low temperature properties of metals (J. W. Edwards, Ann Arbor, Mich., 1947).

[27] E. Orowan, Fracture and strength of solids, Report to Ministry of Supply, United Kingdom (1949).

[28] M. Gensamer, Strength and ductility, Trans. Am. Soc. Metals 36, 30 (1946)

[29] M. Gensamer, The yield point in metals, Trans. Am. Inst. Min. Met. Engrs. 128, 104 (1938).

[30] J. R. Low, Jr. and T. A. Prater, Final report on plastic flow of aluminum aireraft sheet under combined loads-II OSRD Report No. 4052 (Aug. 22, 1944).

[31] J. R. Low, Jr. and F. Garofalo, Precision determination of stress-strain curves in the plastic range, Proc. Soc. Exper. Stress Anal. 4, [2], 16 (1947). 

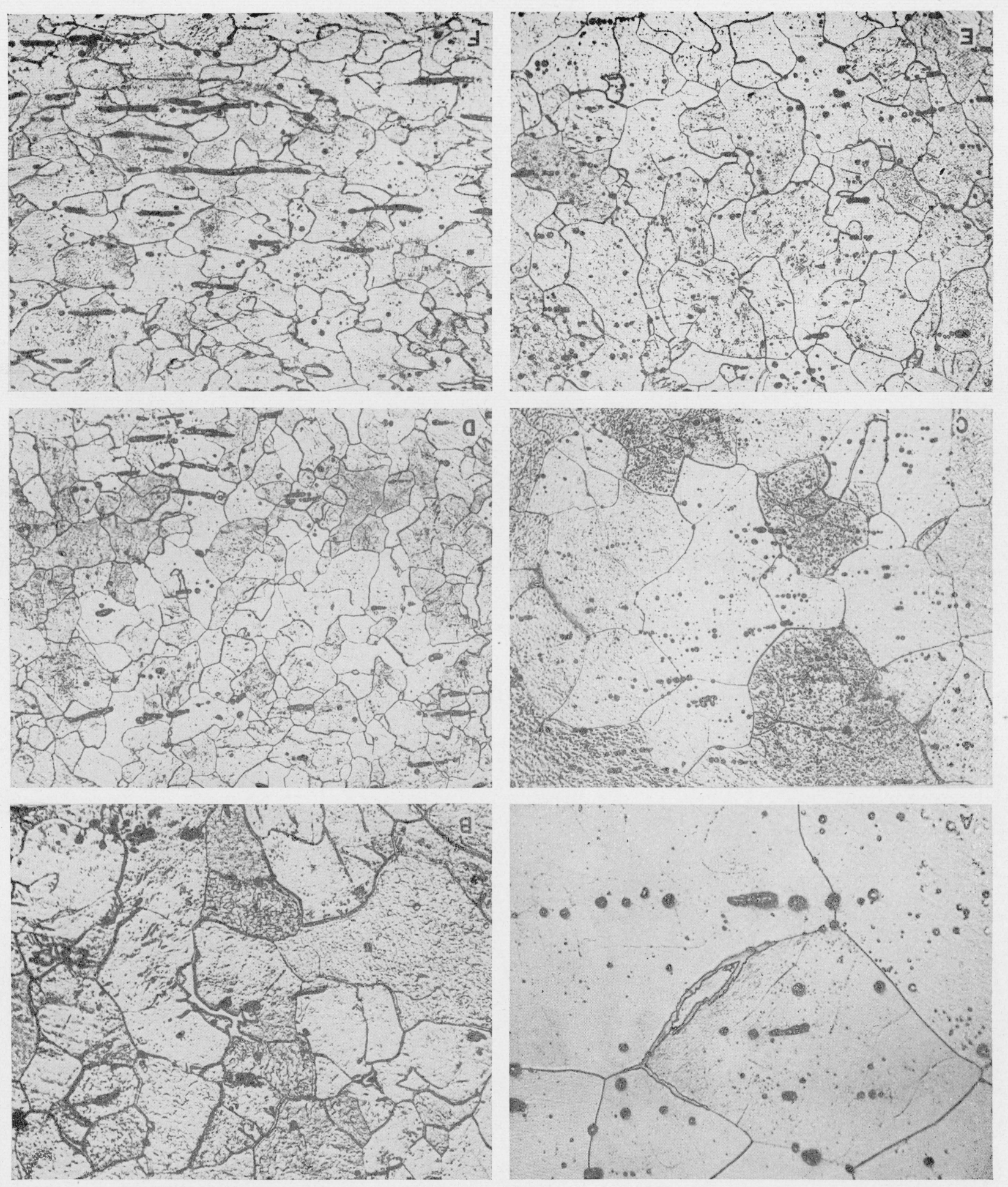

Figure 1. Microstructure of the ingot iron in various initial conditions; etched with 4 -percent nital, $A$ and $B, \times 250$, others $A$ and $C$, annealed; $B$, quenched and tempered; $D$, hot-rolled; $E$, normalized; $F$, cold-drawn to 24-percent reduction of area. 


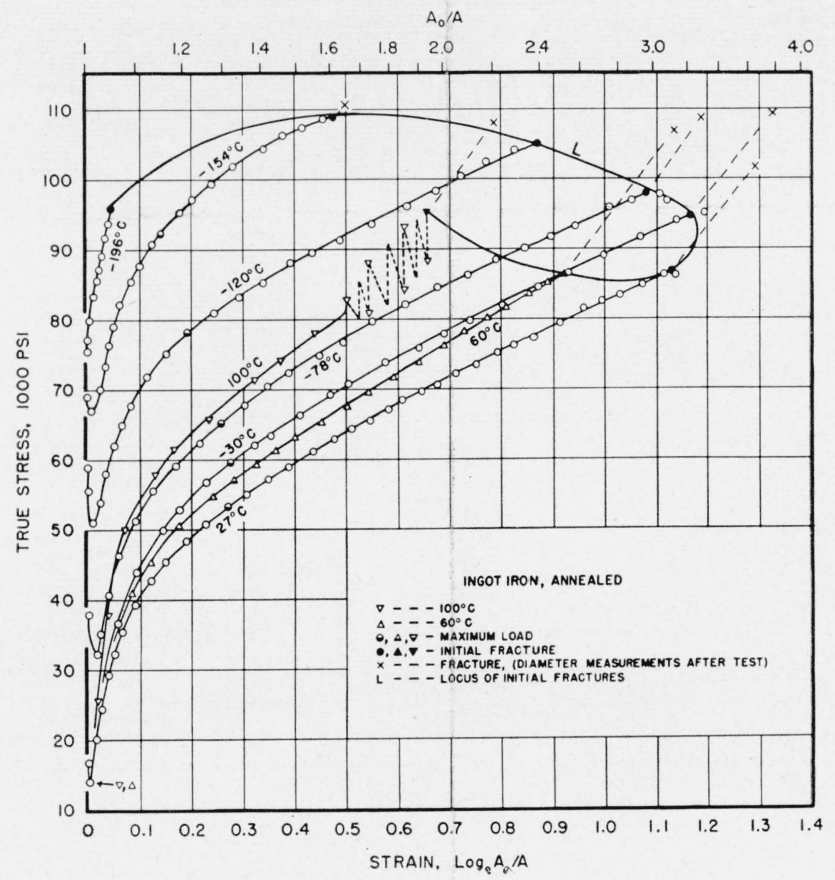

FIGURE 2. True stress-strain curves obtained in tension tests at various temperatures with annealed ingot iron.

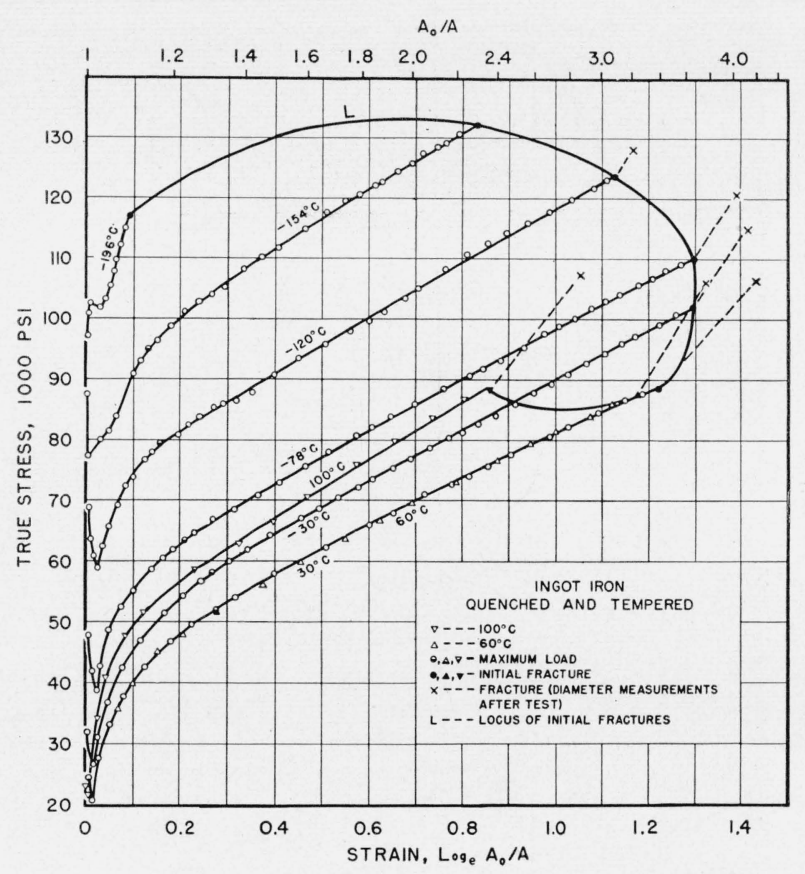

FIGURE 4. True stress-strain curves obtained in tension tests at various temperatures with quenched and tempered ingot iron.

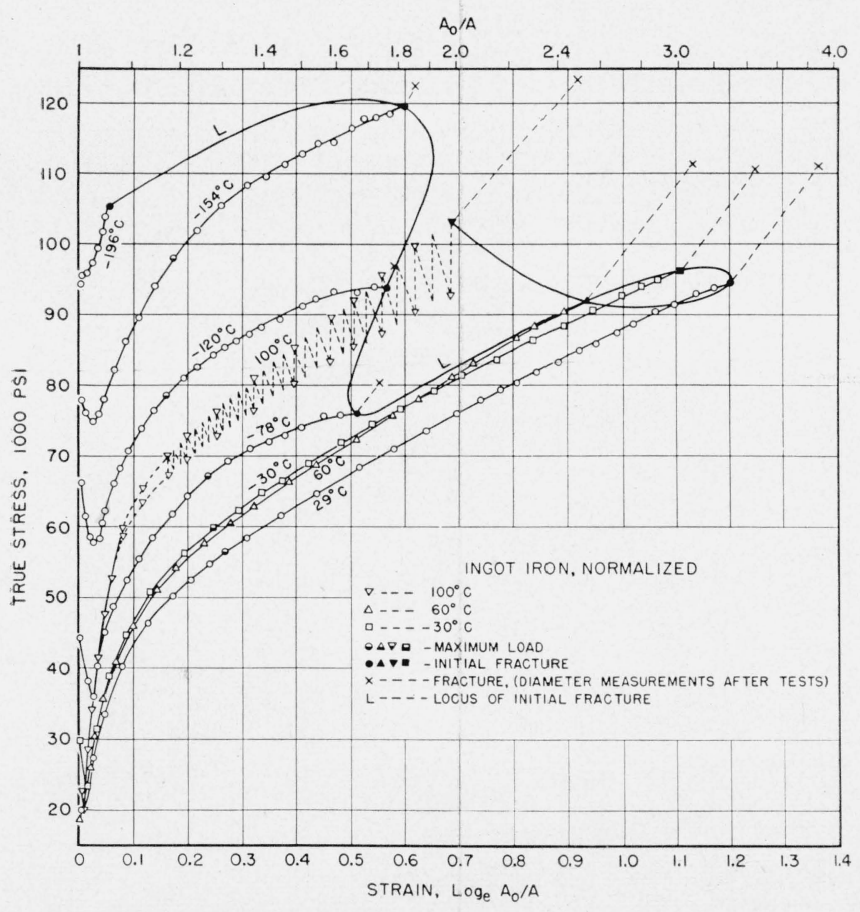

FIGURE 3. True stress-strain curves obtained in tension tests at various temperatures with normalized ingot iron.

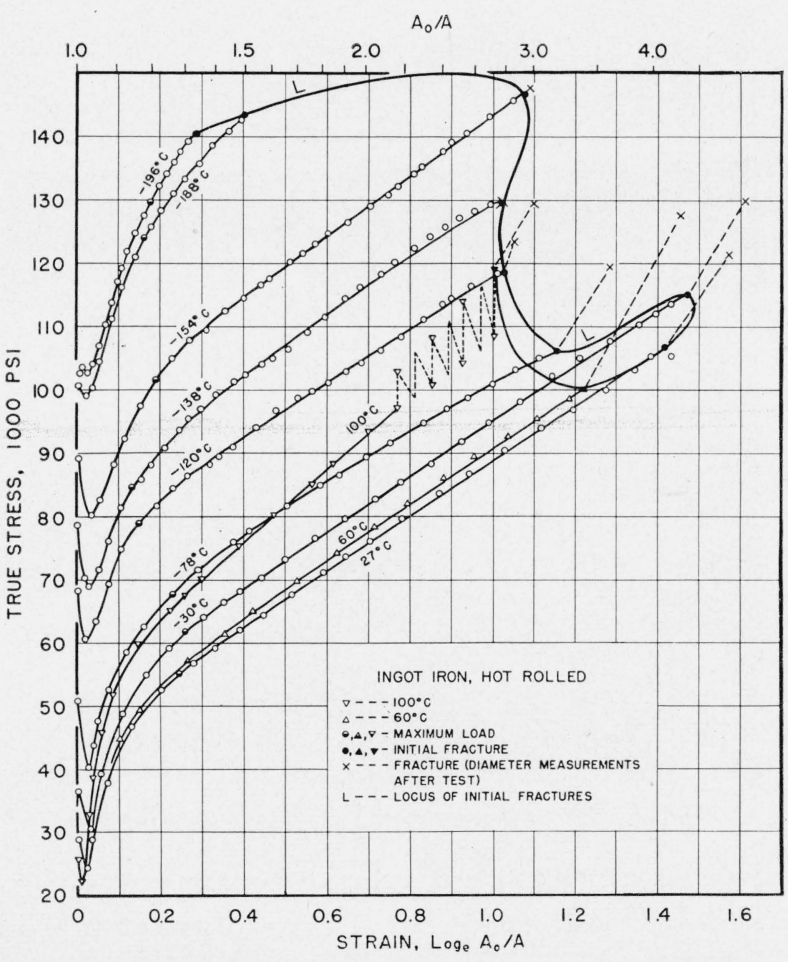

FiguRE 5. True stress-strain curves obtained in tension tests at various temperatures with hot-rolled ingot iron. 


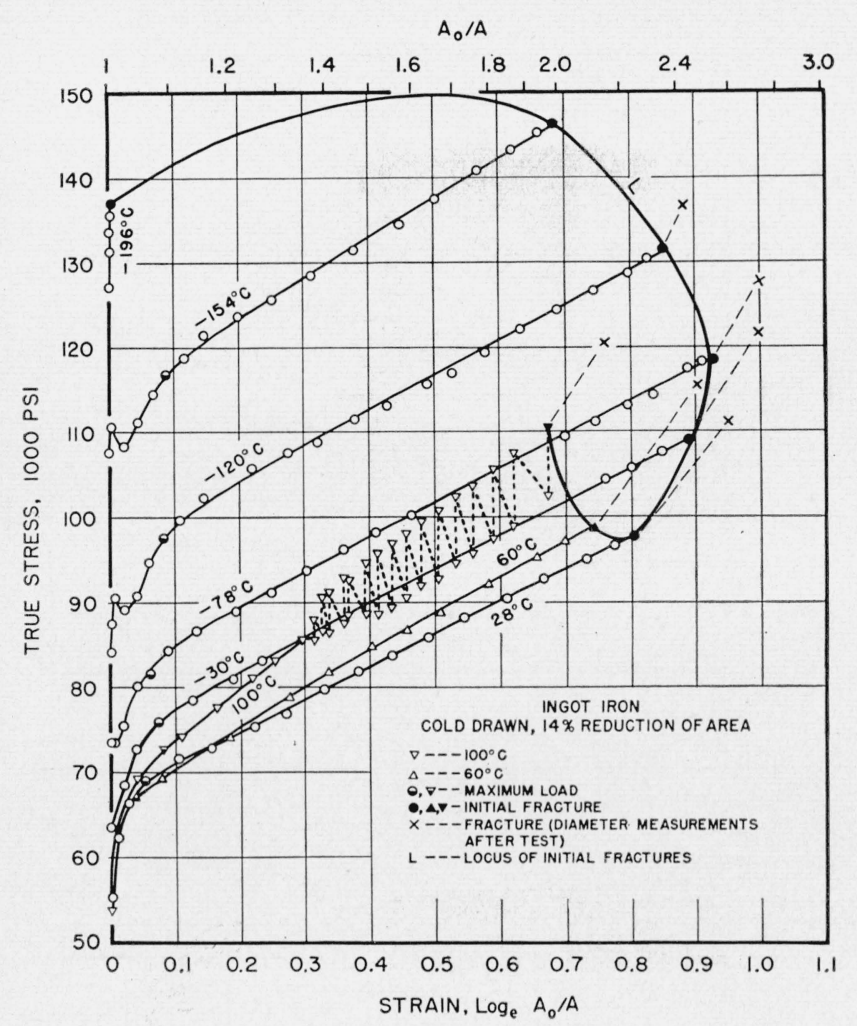

Figure 6. True stress-strain curves obtained in tension tests at various temperatures with ingot iron as cold-drawn, 14percent reduction of area.

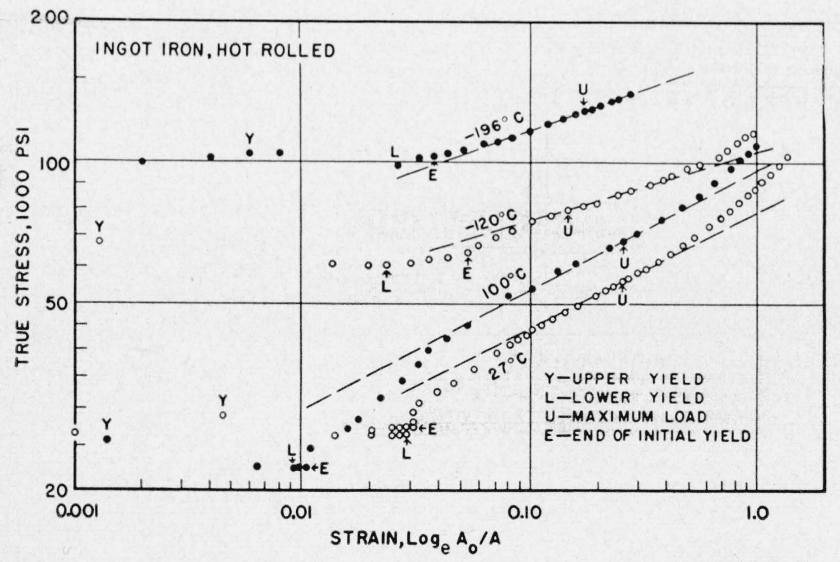

FIGURE 8. Logarithmic true stress-strain curves obtained in tension tests at various temperatures with hot-rolled ingot iron.

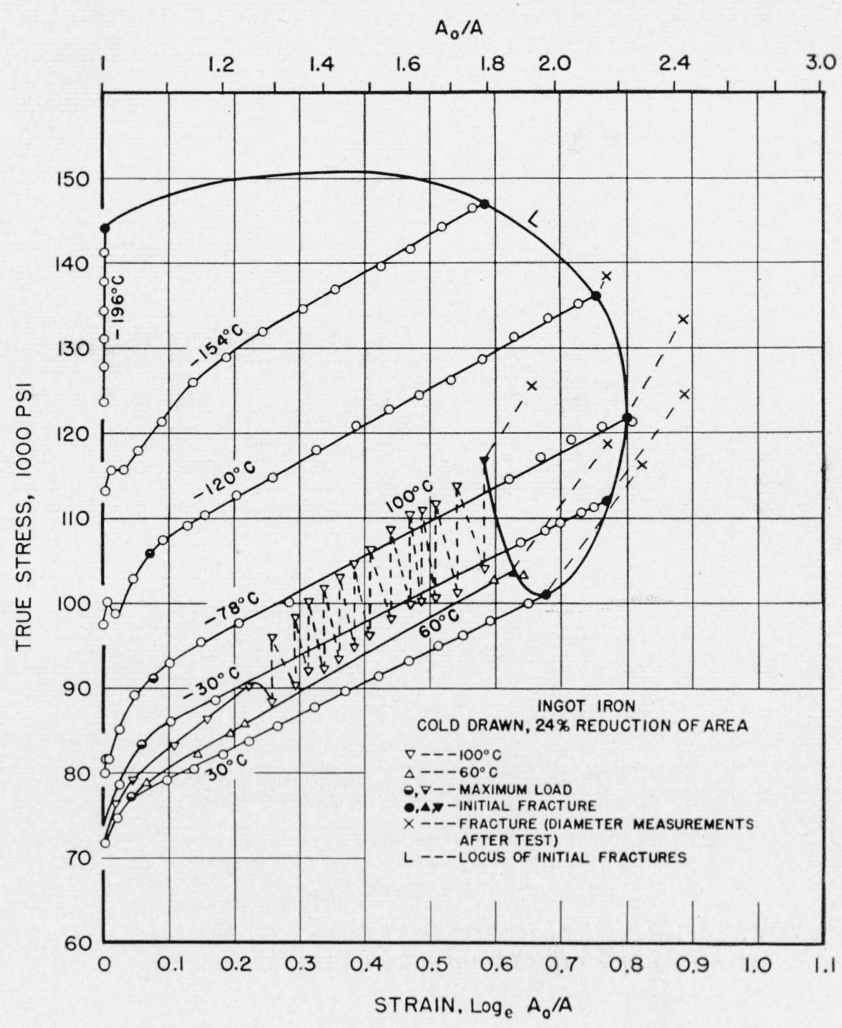

Figure 7. True stress-strain curves obtained in tension tests at various temperatures with ingot iron as cold-drawn, 24percent reduction of area.

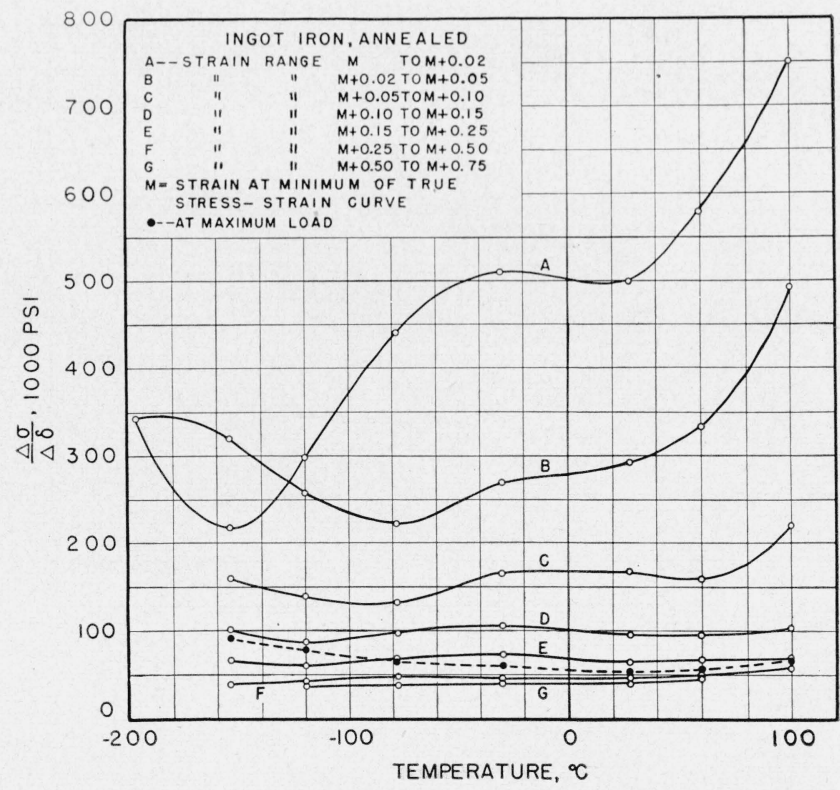

Figure 9. Effect of testing temperature on the rate of workhardening of annealed ingot iron. 


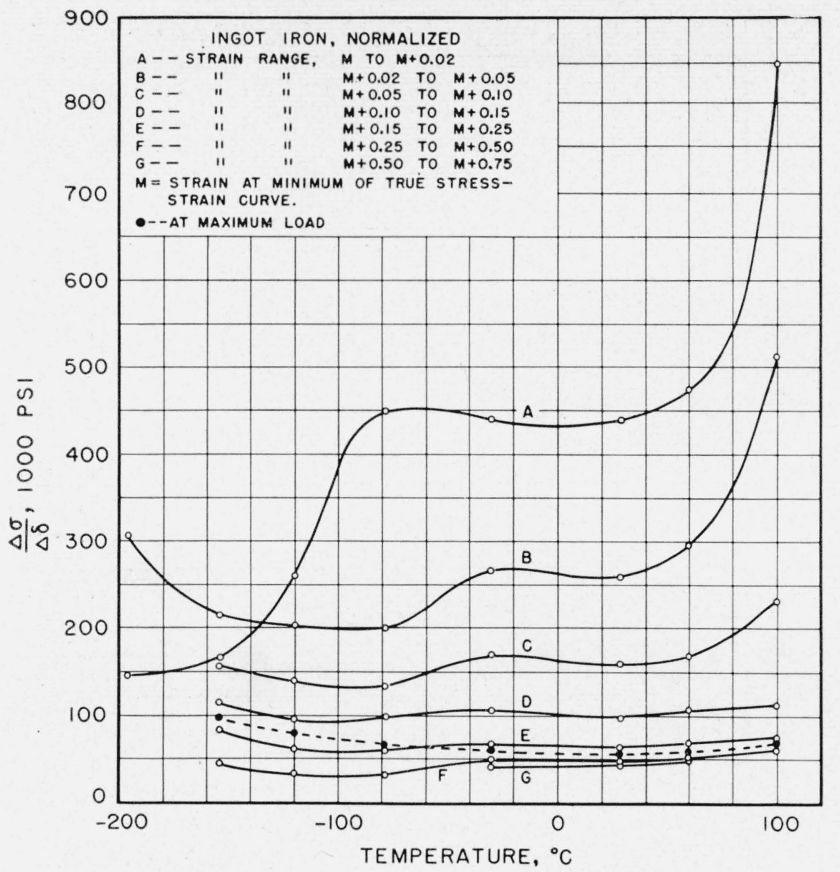

FIGURE 10. Effect of testing temperature on the rate of workhardening of normalized ingot iron.

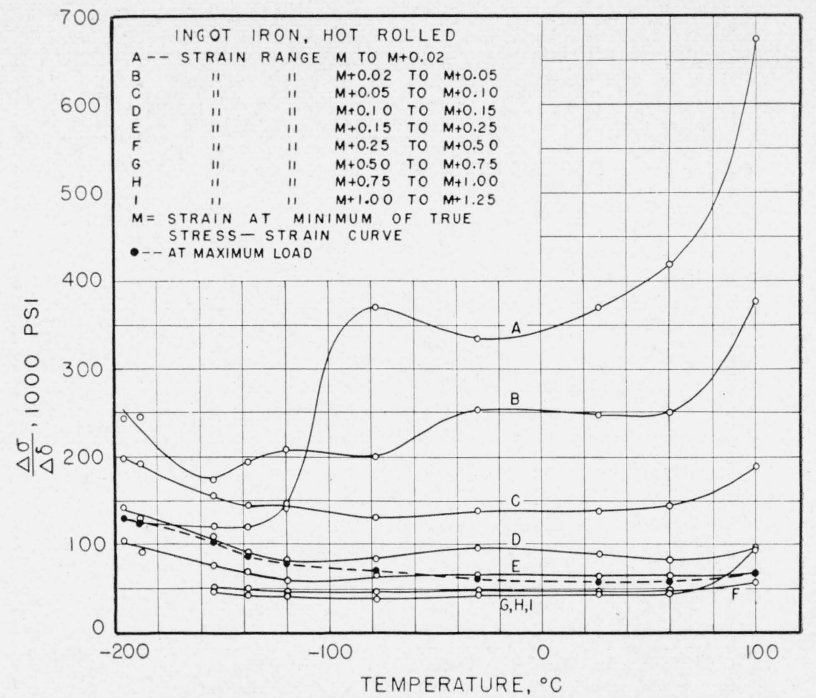

FIGURE 12. Effect of testing temperature on the rate of workhardening of hot-rolled ingot iron.

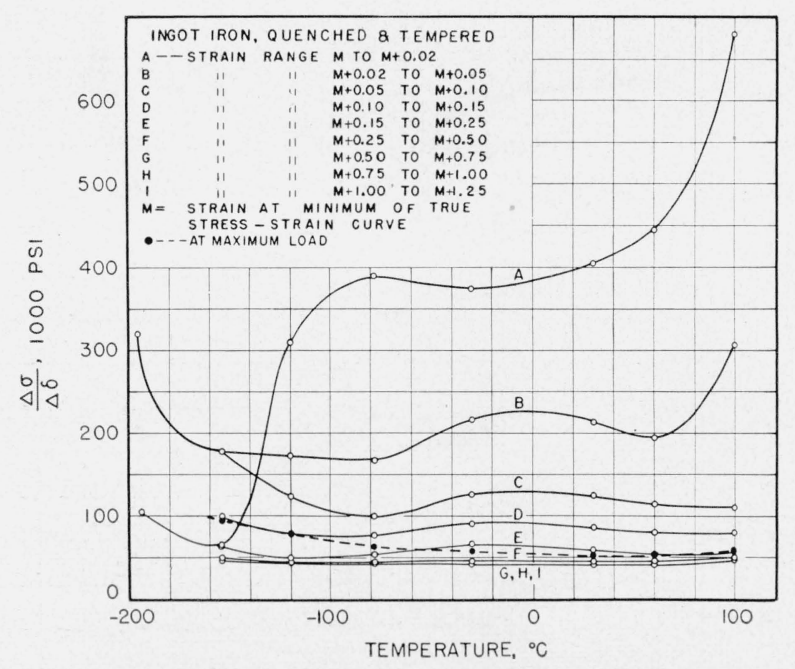

Figure 11. Effect of testing temperature on the rate of workhardening of quenched and tempered ingot iron.

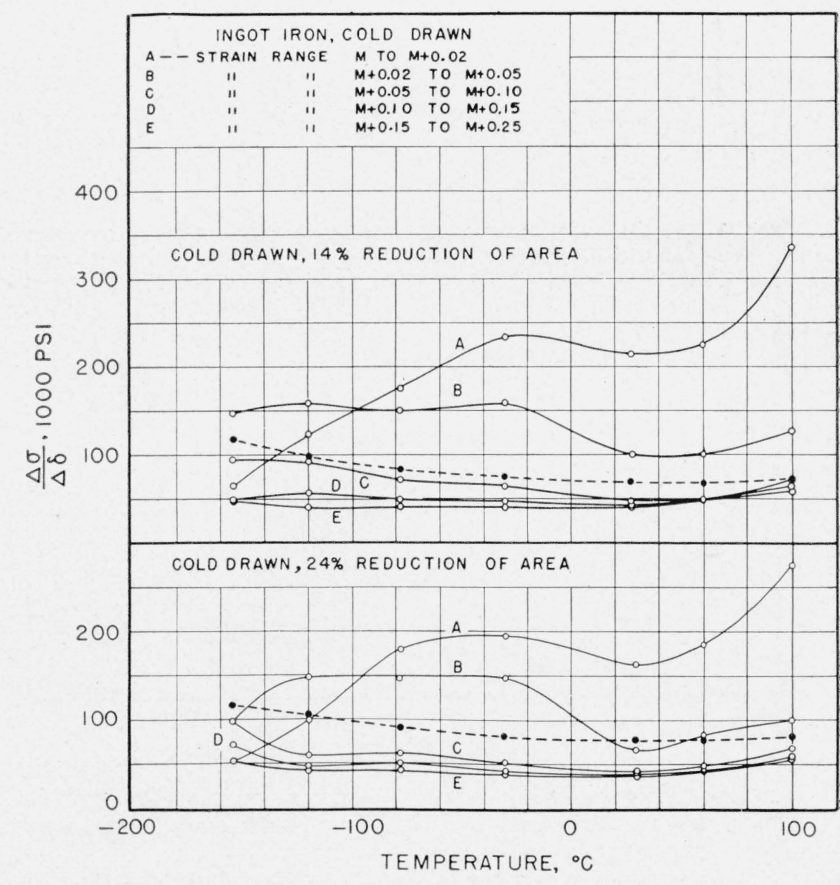

FIGURE 13. Effect of testing temperature on the rate of workhardening of cold-drawn ingot iron. 

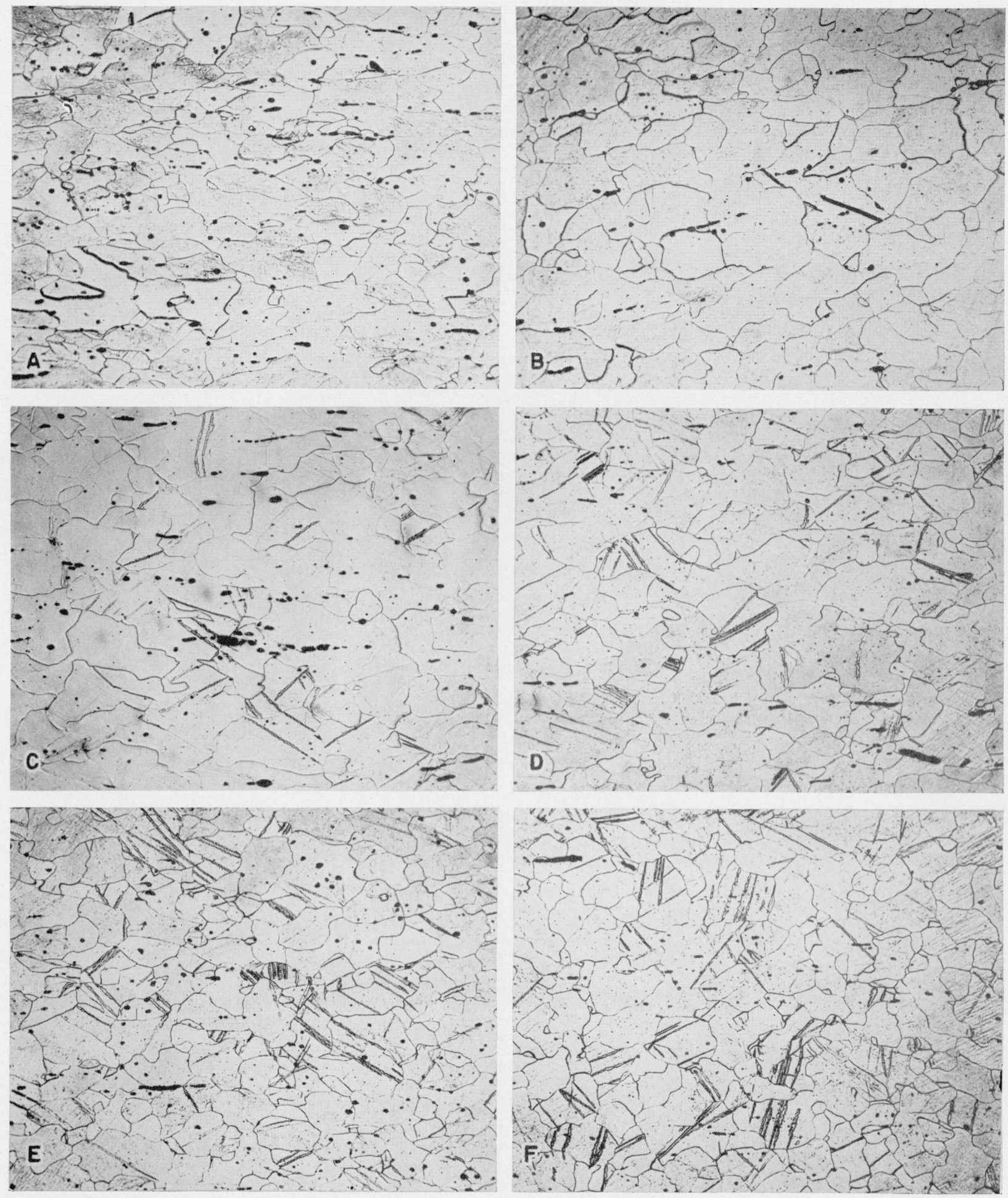

FIGURE 14. Microstructure of the hot-rolled ingot iron after tests in tension at various temperatures. F, Structure 1 in. from fracture, others all $3 / 8$ in. from fracture; etched with 4 -percent nital, $\times 100$.

$A,-120^{\circ} \mathrm{C} ; B,-138^{\circ} \mathrm{C} ; C,-154^{\circ} \mathrm{C} ; D,-188^{\circ} \mathrm{C} ; E$ and $F,-196^{\circ} \mathrm{C}$. 

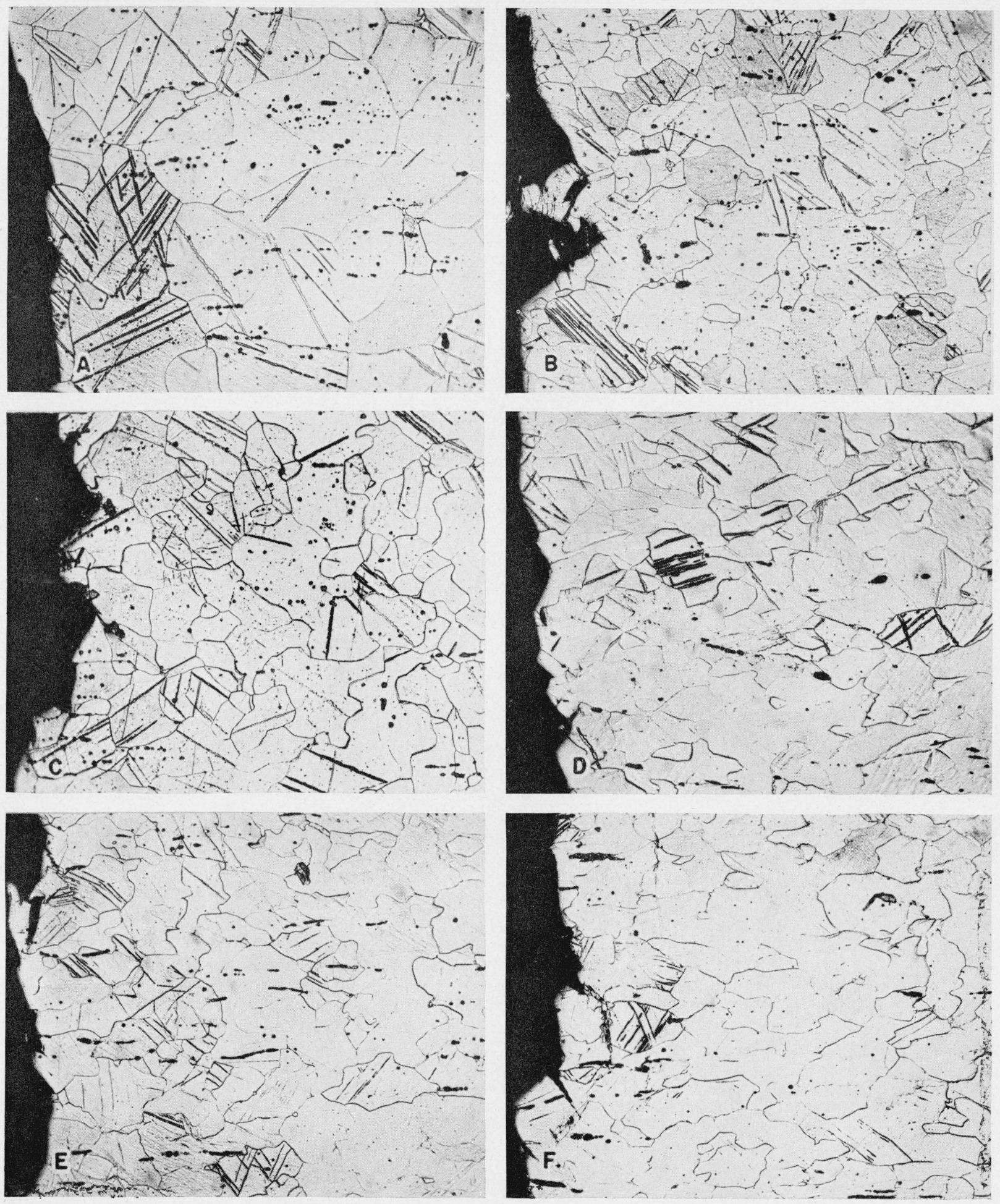

FIGURE 15. Microstructure of the fracture region, after test in tension at $-196^{\circ} \mathrm{C}$ with ingot iron in various conditions; etched with 4 percent nital, $\times 100$.

$A$, annealed; $B$, quenched and tempered; $C$, normalized; $D$, hot-rolled; $E$, cold-drawn, 14-percent reduction of area; $F$, cold-drawn, 24-percent reduction
of area. 


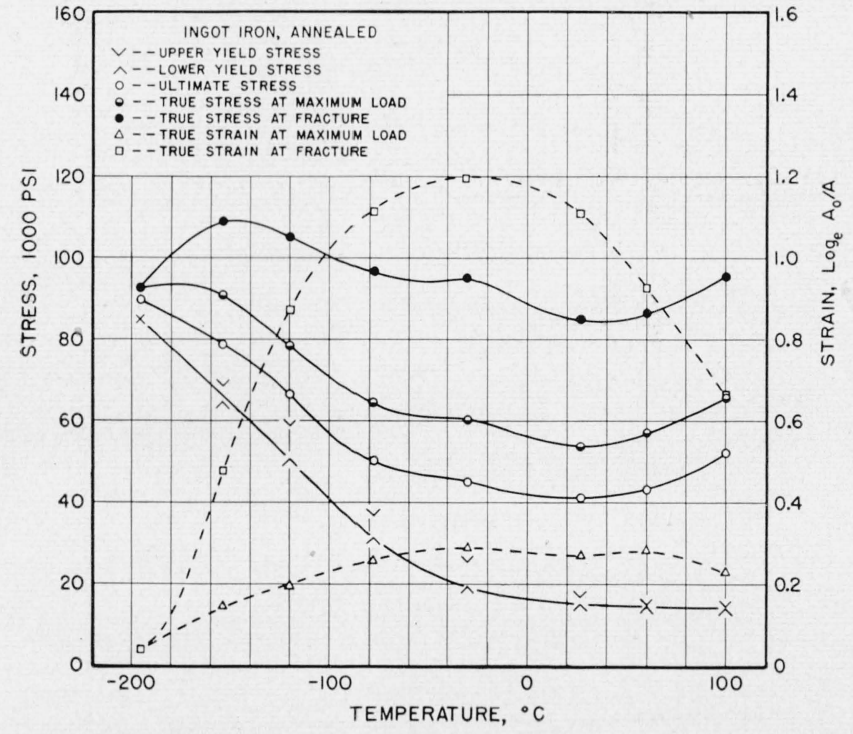

FIGURE 16. Effect of testing temperature on various mechanical properties of the annealed ingot iron.

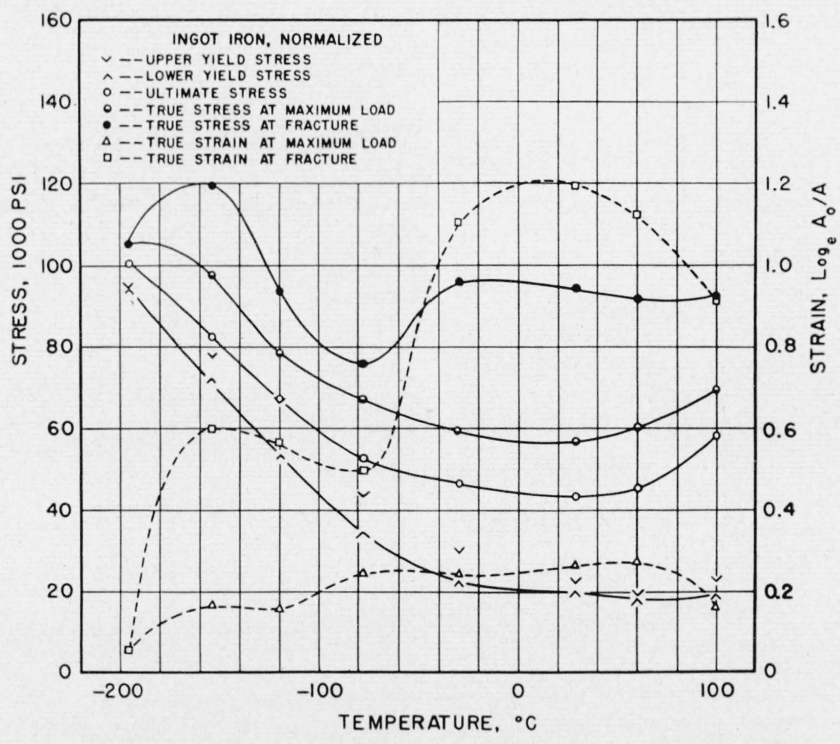

FIGURE 17. Effect of testing temperature on various mechanical properties of the normalized ingot iron.

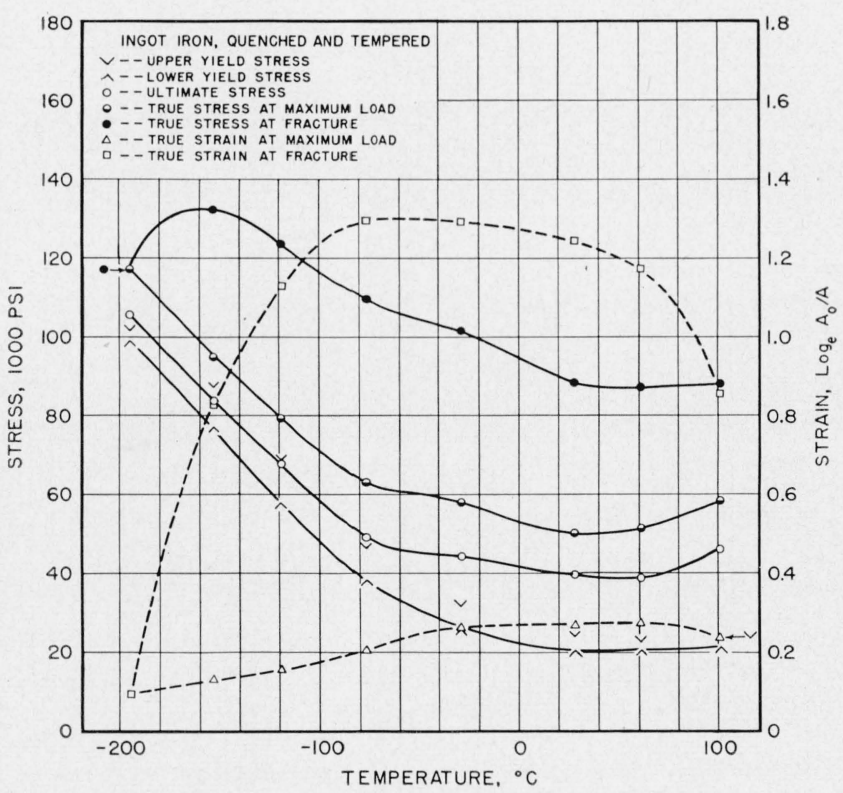

FIGURE 18. Effect of testing temperature on various mechanical properties of the quenched and tempered ingot iron.

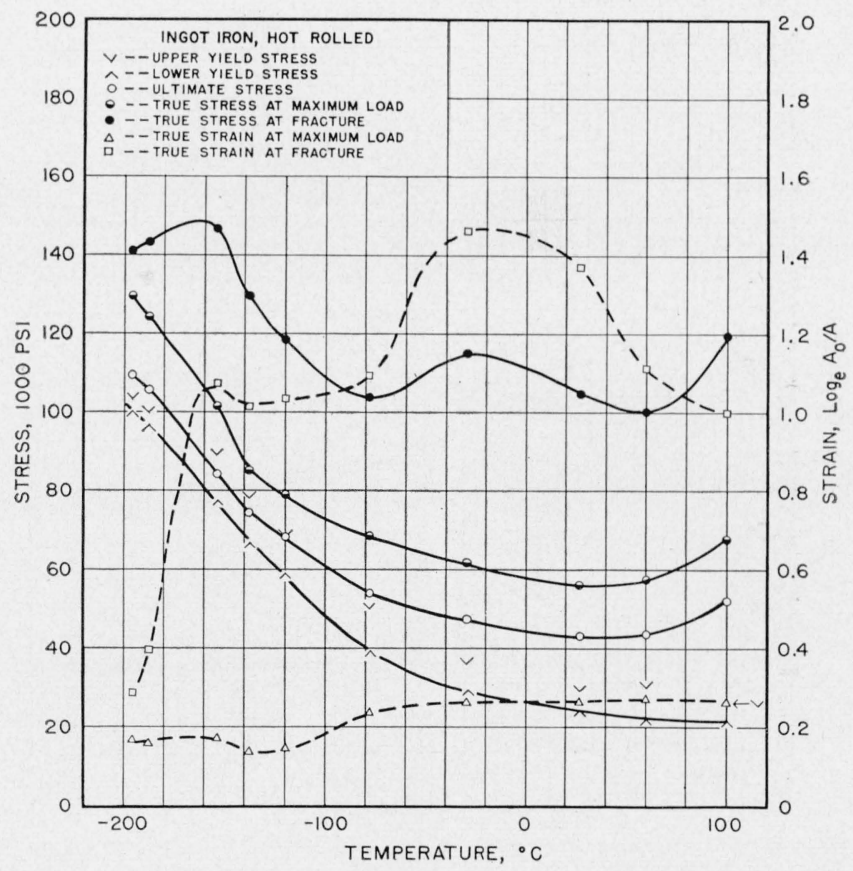

Figure 19. Effect of testing temperature on various mechanical properties of the hot-rolled ingot iron. 


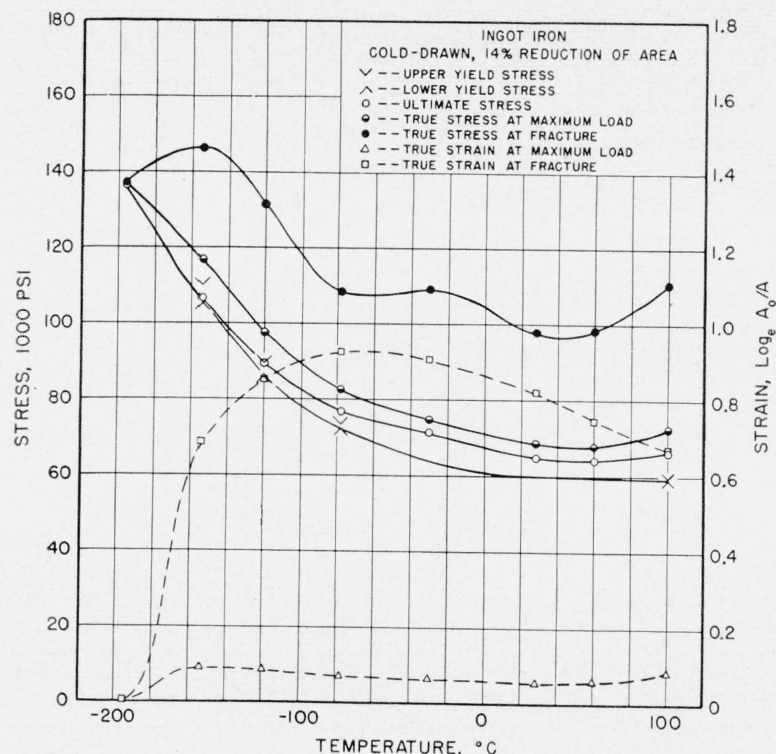

FiguRE 20. Effect of testing temperature on various mechanical properties of the ingot iron as cold-drawn, 14-percent reduction of area.

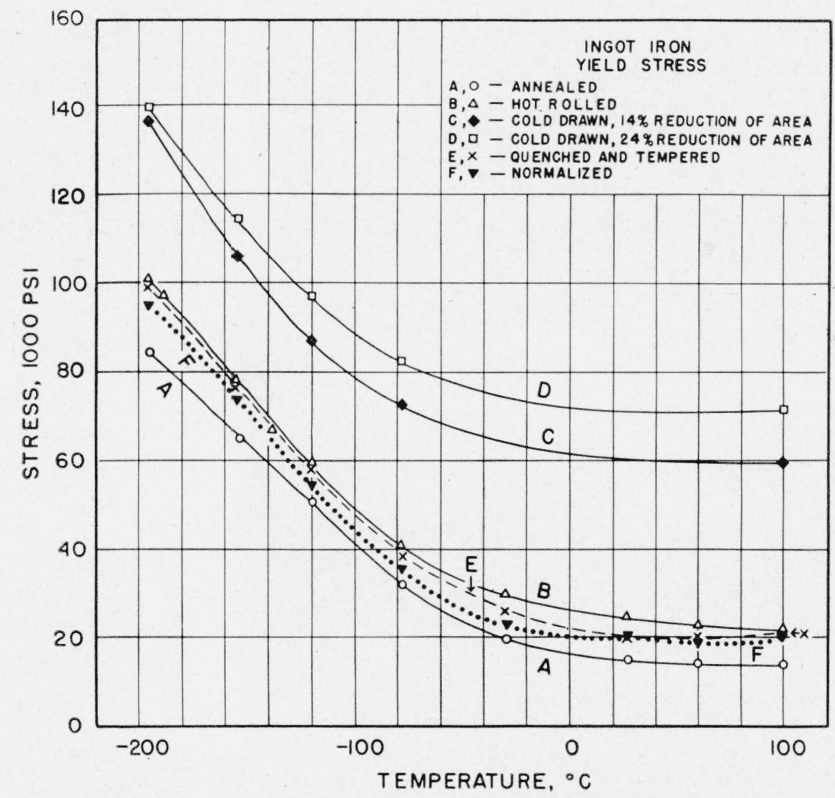

FIGURE 22. Effect of testing temperature and the initial condition of the ingot iron on the lower yield stress.

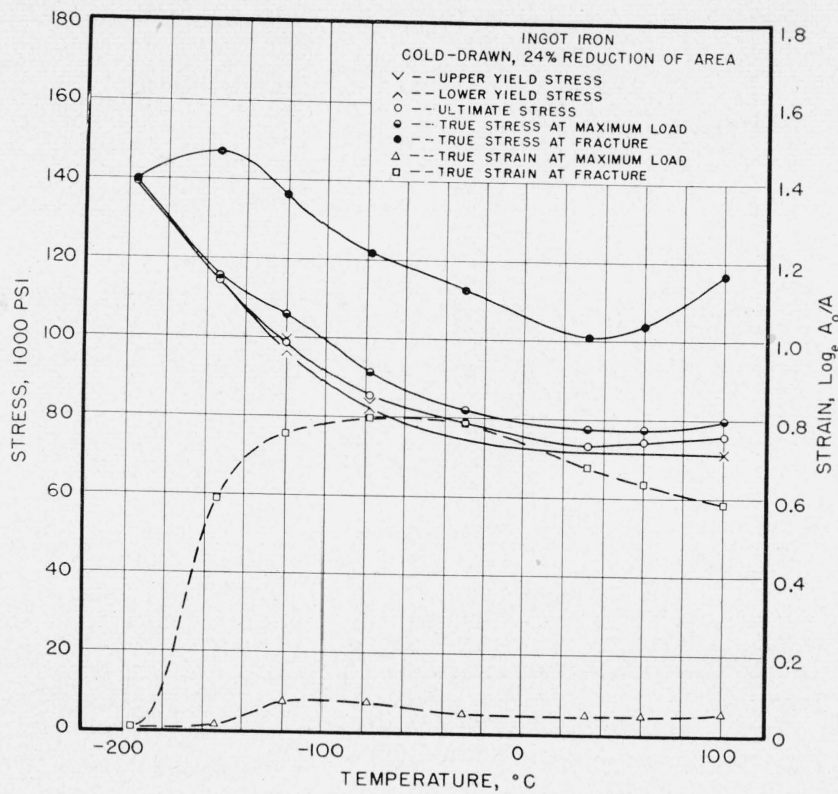

FIGURE 21. Effect of testing temperature on various mechanical properties of the ingot iron as cold-drawn, 24-percent reduction of area.

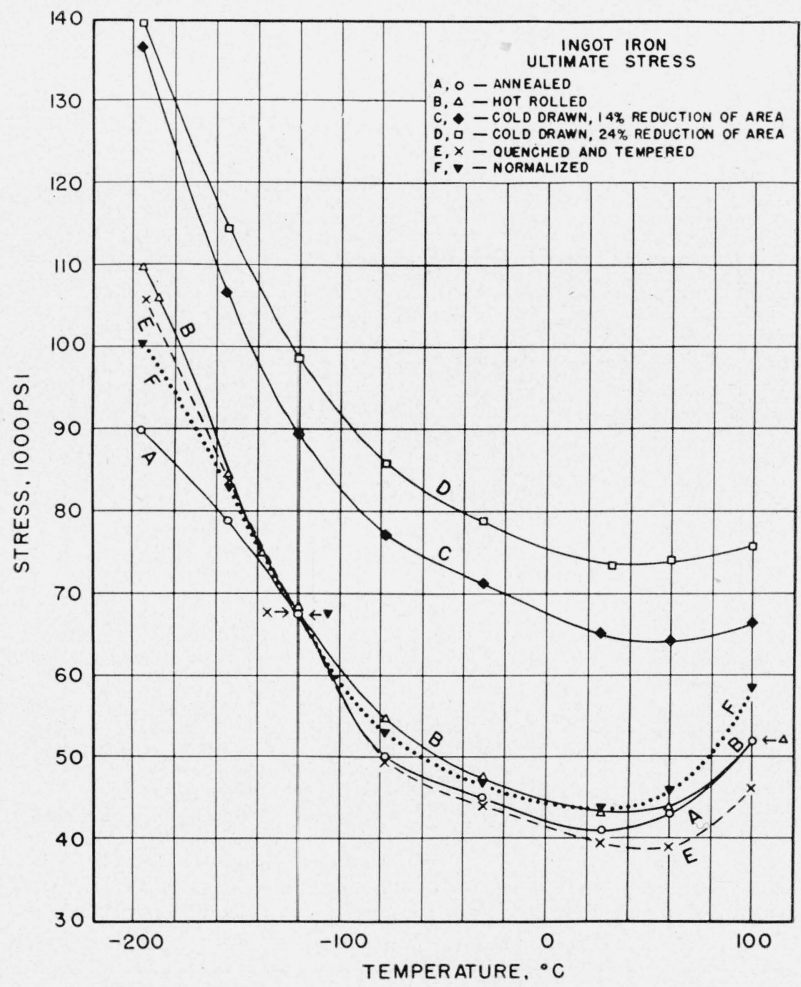

Figure 23. Effect of testing temperature and the initial condition of the ingot iron on the ultimate stress. 


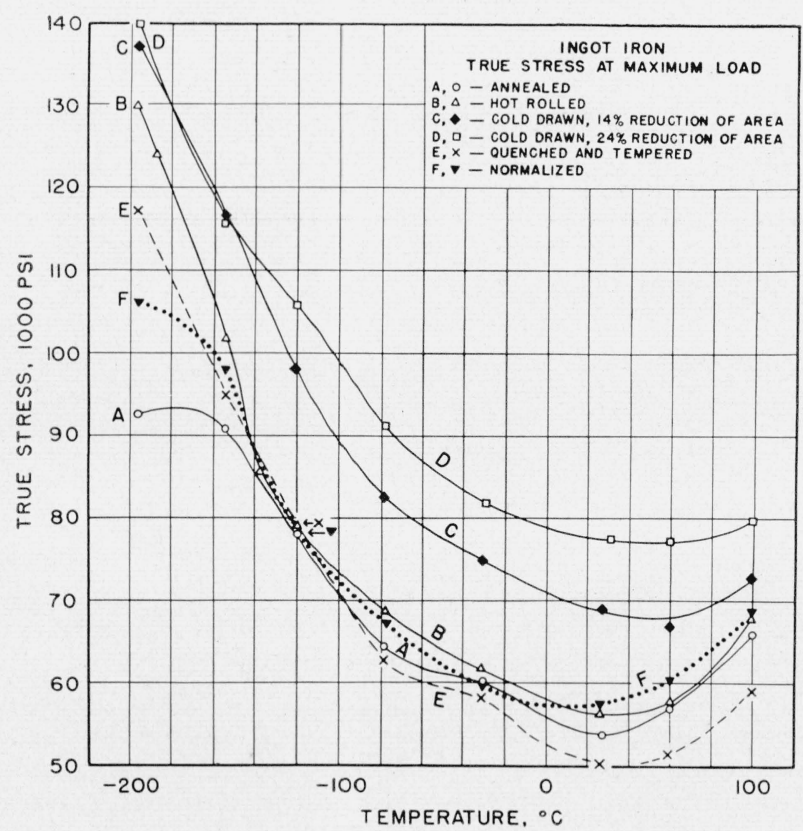

Figure 24. Effect of testing temperature and the initial condition of the ingot iron on the true stress at maximum load.

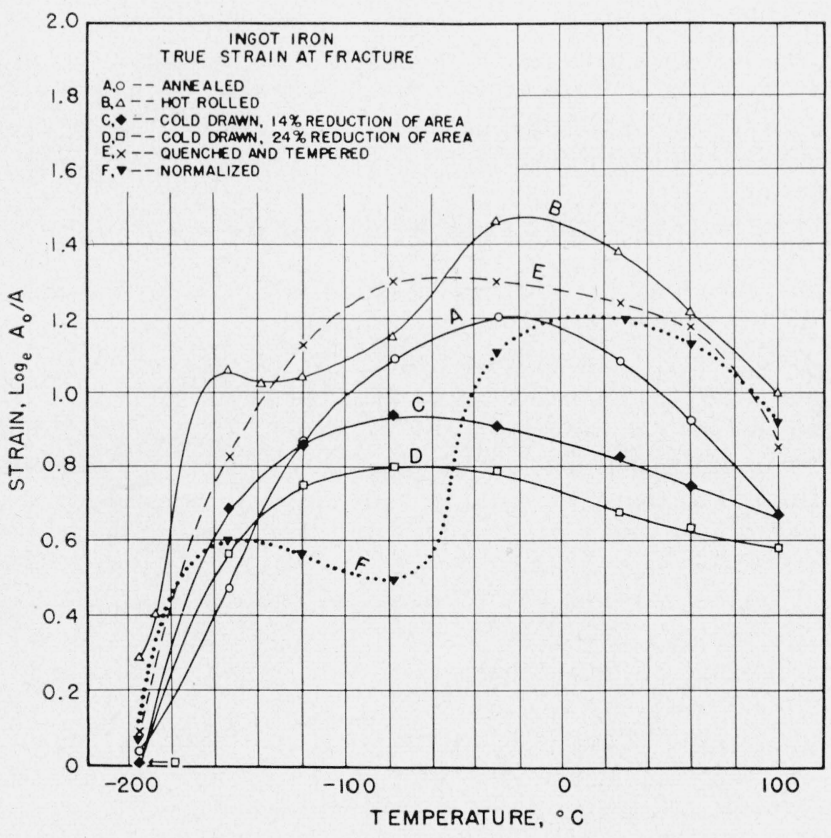

FIGURE 26. Effect of testing temperature and the initial condition of the ingot iron on the strain at initial fracture.

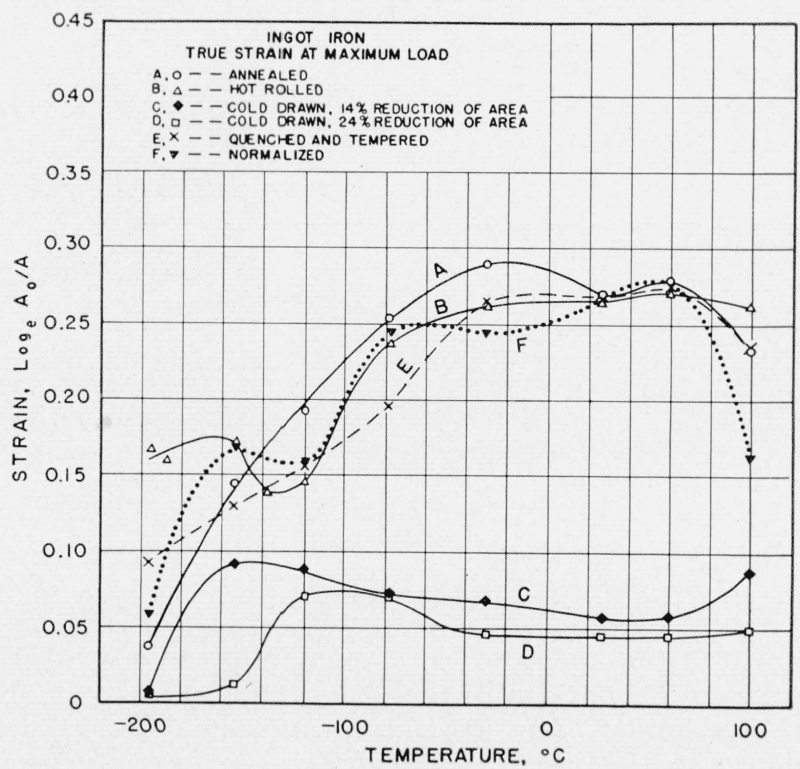

FIGURE 25. Effect of testing temperature and the initial condition of the ingot iron on the strain at maximum load.

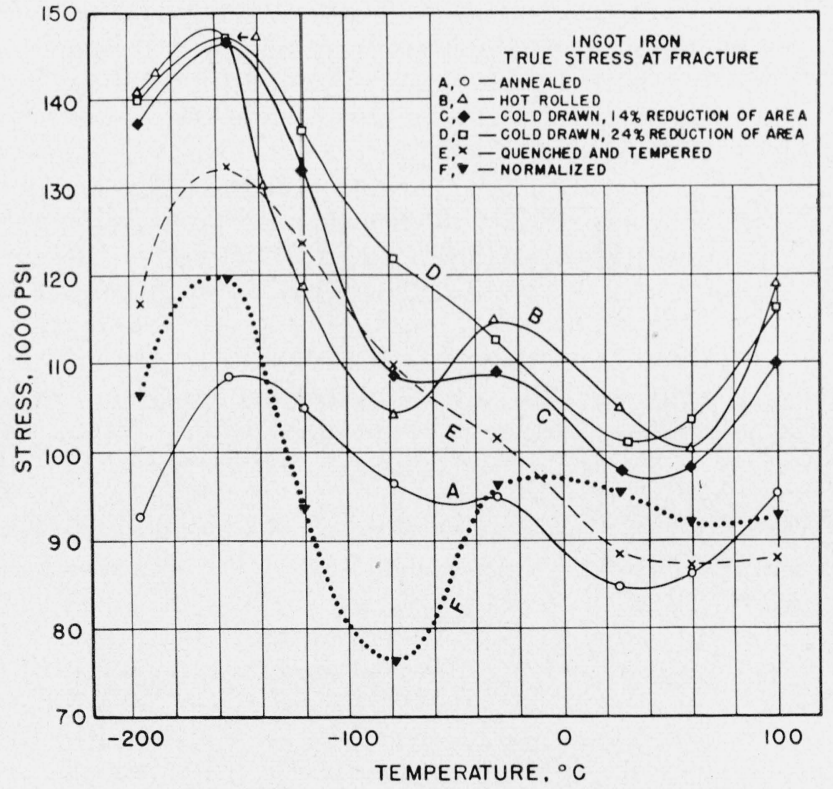

FIGURE 27. Effect of testing temperature and the initial condition of the ingot iron on the true stress at initial fracture.

Washington, April 11, 1950. 